NBER WORKING PAPER SERIES

HOW DOES HEDGE FUND ACTIVISM RESHAPE CORPORATE INNOVATION?

\author{
Alon Brav \\ Wei Jiang \\ Song Ma \\ Xuan Tian \\ Working Paper 22273 \\ http://www.nber.org/papers/w22273 \\ NATIONAL BUREAU OF ECONOMIC RESEARCH \\ 1050 Massachusetts Avenue \\ Cambridge, MA 02138 \\ May 2016
}

The authors have benefited from discussions with Taylor Begley, Sharon Belenzon, Nittai Bergman, Shai Bernstein, Thomas Keusch, Adrien Matray, Frank Partnoy and comments from seminar and conference participants at Baruch College, Interdisciplinary Center at Herzliya, Hebrew University, Kellogg, NC State, Purdue, Rice University, Tel-Aviv University, Washington University in St. Louis, University of Southern California, Yeshiva University, the 2015 AFA Annual Meetings, the 2015 BI Conference on Corporate Governance, the June 2015 Academic day at London Business School's Centre for Corporate Governance, University of San Diego/Vanderbilt Conference on the Future of Research on Hedge Fund Activism, the 2015 Ackerman Chair Corporate Governance Conference, the 2015 NHH Center for Corporate Finance Conference, and the 2016 Weinberg Corporate Governance Symposium. Alon Brav can be reached at phone: (919) 660-2908, email: brav@duke.edu. Wei Jiang can be reached at phone: (212) 854-9002, email: wj2006@columbia.edu. Song Ma can be reached at phone: (919) 660-1964, email: song.ma@duke.edu. Xuan Tian can be reached at phone: (812) 855-3420, email: tianx@indiana.edu. The views expressed herein are those of the authors and do not necessarily reflect the views of the National Bureau of Economic Research.

NBER working papers are circulated for discussion and comment purposes. They have not been peer-reviewed or been subject to the review by the NBER Board of Directors that accompanies official NBER publications.

(C) 2016 by Alon Brav, Wei Jiang, Song Ma, and Xuan Tian. All rights reserved. Short sections of text, not to exceed two paragraphs, may be quoted without explicit permission provided that full credit, including $\odot$ notice, is given to the source. 
How Does Hedge Fund Activism Reshape Corporate Innovation?

Alon Brav, Wei Jiang, Song Ma, and Xuan Tian

NBER Working Paper No. 22273

May 2016

JEL No. G23,G3,G34,O31

\section{ABSTRACT}

This paper studies how hedge fund activism reshapes corporate innovation. Firms targeted by hedge fund activists experience an improvement in innovation efficiency during the five-year period following the intervention. Despite a tightening in $R \& D$ expenditures, target firms experience increases in innovation output, measured by both patent counts and citations, with stronger effects seen among firms with more diversified innovation portfolios. We also find that the reallocation of innovative resources and the redeployment of human capital contribute to the refocusing of the scope of innovation. Finally, additional tests refute alternative explanations attributing the improvement to mean reversion, sample attrition, management's voluntary reforms, or activists' stock-picking abilities.

Alon Brav

Fuqua School of Business

Duke University

One Towerview Drive

Durham, NC 27708

and NBER

brav@duke.edu

Wei Jiang

Graduate School of Business

Columbia University

3022 Broadway, Uris Hall 803

New York, NY 10027

and NBER

wj2006@columbia.edu
Song Ma

Duke University's Fuqua School of Business

100 Fuqua Dr

Durham, NC 27708

song.ma@duke.edu

Xuan Tian

BU 370 Finance Department

Kelley School of Business

Indiana University

1309 E. Tenth Street

Bloomington, IN 47405

tianx@indiana.edu 


\title{
How Does Hedge Fund Activism Reshape Corporate Innovation?
}

\begin{abstract}
This paper studies how hedge fund activism reshapes corporate innovation. Firms targeted by hedge fund activists experience an improvement in innovation efficiency during the five-year period following the intervention. Despite a tightening in $\mathrm{R} \& \mathrm{D}$ expenditures, target firms experience increases in innovation output, measured by both patent counts and citations, with stronger effects seen among firms with more diversified innovation portfolios. We also find that the reallocation of innovative resources and the redeployment of human capital contribute to the refocusing of the scope of innovation. Finally, additional tests refute alternative explanations attributing the improvement to mean reversion, sample attrition, management's voluntary reforms, or activists' stock-picking abilities.
\end{abstract}

JEL Classification: G23, G34, O31

Keywords: Hedge fund activism, Innovation, Resource allocation, Human capital redeployment

\section{Introduction}

Since the rise of shareholder rights in the 1980s, there has been an ongoing debate among academics, practitioners, and policymakers about the consequences of stock market pressure on managerial incentives to engage in innovative activities that have long-term value consequences but are not easily assessed by the market. The idea that stock market pressure leads to "managerial myopia" has been a recurring concern (Stein $(1988,1989))$ and has evolved into a heated debate in recent years as activist hedge funds have come to epitomize shareholder empowerment. The concern reached a heightened level in 2015 when Laurence Fink, the chairman and CEO of BlackRock, the world's largest institutional investor, argued that activist investors put pressure on and create incentives for corporate leaders to generate short-terms gains at the expense of long-term value creation. ${ }^{1}$

Between 1994 and 2007, there were more than 2,000 engagements by hedge fund activists in which hedge funds proposed changes to payout policies, business strategies, and corporate governance, often publicly and aggressively. Recent studies, covering both the U.S. and international markets, have

\footnotetext{
${ }^{1}$ In a letter sent to chief executives of the 500 largest publicly traded U.S. companies Fink stresses the importance of taking a long-term approach to creating value and his concern with management "...response to the acute pressure, growing with every quarter, for companies to meet short-term financial goals at the expense of building long-term value. This pressure originates from a number of sources-the proliferation of activist shareholders seeking immediate returns, ..." See blackrock.com, "Delivering Long-Term Value - Letter to Corporates," March 31, 2015.
} 
documented that the target firm's stock price increases 5\% to $7 \%$ when the market first learns of the activist's intervention. Moreover, the interventions are not followed by a decline in either stock returns or operating performance during the five-year window after the arrival of the activists. ${ }^{2}$ Yet, measurement of the long-term impact of hedge fund activism has proven challenging to evaluate due to data restrictions and methodological limitations. As a result, opponents of hedge fund activism have resorted to a "myopic activists" view, claiming that activists' agendas are biased towards the pursuit of short-term stock gains at the expense of firms' long-term values. ${ }^{3}$

Our goal is to inform the debate by analyzing how hedge fund activism reshapes corporate innovation-arguably the most important long-term investment that firms make but also the most susceptible to short-termism. ${ }^{4}$ A priori, neither the direction nor the magnitude of activists' impact on overall innovative activities is clear. First, activists might have a negative impact on innovation because, as Holmstrom (1989) argued, innovative activities involve the exploration of untested and unknown approaches that have a high probability of failure with contingencies that are impossible to foresee. Given the lack of observability and predictability, the concern is that management might respond to pressure from current shareholders by adopting investment/innovation policies that are detrimental to long-term firm value. More powerful current shareholders could lead to greater misalignment. ${ }^{5}$

Second, although managerial preferences and objectives may not be aligned with firm value maximization, the order of the relative preference is not clear a priori. Like any other investment decision,

${ }^{2}$ See Brav, Jiang, Partnoy, and Thomas (2008), Clifford (2008), Klein and Zur (2009), Greenwood and Schor (2009), He, Qiu, and Tang (2014), and Krishnan, Partnoy and Thomas (2015) for U.S. companies; and Becht, Franks, Mayer, and Rossi (2009), Becht, Franks, Grant and Wagner (2015) for non-U.S. markets. For general information about hedge fund activism see Brav, Jiang, and Kim (2015a).

${ }^{3}$ See Bebchuk, Brav, and Jiang (2015) and Coffee and Palia (2015) for detailed discussions regarding the debate.

${ }^{4}$ In the same letter as referenced in Footnote 1, Fink then argues that, "In the face of these pressures, more and more corporate leaders have responded with actions that can deliver immediate returns to shareholders, such as buybacks or dividend increases, while underinvesting in innovation, skilled workforces or essential capital expenditures necessary to sustain long-term growth."

${ }^{5}$ Activist hedge funds have targeted R\&D policies at technology powerhouses Microsoft, Google, and Apple in recent years. See, "Hedge Fund Activism in Technology and Life Science Companies" in the Harvard Law School Forum on Corporate Governance and Financial Regulation, April 17, 2012. Such engagements are exemplified in the recent hostile intervention by Trian Partners at DuPont, an R\&D powerhouse. See, "DuPont's R\&D Is at Center of Fight With Activist," The Wall Street Journal, Oct 27, 2014. The fund criticized DuPont's R\&D efforts, proposing that the company consider splitting its agriculture, nutrition and health, and industrial biosciences divisions from its materials businesses. 
a firm should only engage in innovative activities that offer an expectation of positive net present value (NPV), and agency problems may lead to either over- or under-investment. For example, over-investment may arise if specialized investment entrenches the management (Scharfstein and Stein (2002)) or if managers derive private benefits from such activities (e.g., "grandstanding" suggested by Gompers (1996)). In such a scenario, shareholders can legitimately demand that firms spend fewer resources on innovative activities. The opposite is also plausible since agency problems may lead to under-investment: Shareholders may demand higher levels of research and development (R\&D) than management wants if diversified investors have more capacity to absorb innovation risk (Aghion, Van Reenen, and Zingales (2013)).

To set the stage, we first examine innovation activities at target firms before and after hedge fund intervention, measured by both inputs ( $R \& D$ expenditures) and outputs (patent quantity and quality). Consistent with previous findings that target firms reduce investment and streamline their asset base following the intervention, we find that $R \& D$ spending drops significantly in absolute amount during the five-year window subsequent to hedge fund activism. Interestingly, there does not appear to be a reduction in output from innovation—-measured by patent counts and citation counts per patent—after the intervention. Consistent with the idea that target firms' innovation efficiency improves after hedge fund intervention, most of these measures increase significantly.

Next, we explore three mechanisms through which hedge fund activism impacts targeted firms' innovation efficiency. First, the improvement in patent counts and number of citations per patent is driven by firms with a diverse portfolio of patents prior to the intervention that refocused their efforts after the arrival of activists. Moreover, the increase in innovation is concentrated in technological areas that are central to the core capabilities of the target firms. This set of results constitutes preliminary evidence that firms tend to improve innovation efficiency in the period following the intervention by allocating internal innovation capacity to key areas of expertise.

Second, hedge fund intervention is followed by a more active and efficient reallocation of outputs from innovation. Specifically, target firms sell an abnormally high number of existing patents compared 
to their matched peer firms, and patents sold are those that are less related to their technological expertise. Moreover, patents sold post hedge fund intervention receive a significantly higher number of citations relative to their own history and matched peers. These patterns do not appear prior to the intervention, suggesting that the higher rate of patent transactions matching peripheral patents to new and better-suited owners represent efficient reallocation of innovation outputs, a plausible channel to the observed efficiency gain.

The third mechanism involves the redeployment of innovators at target firms following the intervention. We examine the productivity, in terms of both patents filed and citations per patent, separately for inventors who stay with or leave the targeted firms and any new hires. A set of coherent patterns emerge: The inventors retained by target firms are more productive than "stayers" at non-target peers; the inventors who leave following hedge fund intervention are more productive with their new employers; and finally, the inventors newly hired post intervention are of similar productivity at the new firm. Combined, the reshuffling of human capital post intervention brings about efficiency gains because the key innovative personnel are matched or re-matched to work environments where they can be more productive.

While the evidence above is consistent with the view that hedge fund activists impact target firms' innovation, it does not provide conclusive identification of a causal effect. It may be argued activists are better able to anticipate these changes, and the above results might be largely driven by the nonrandom selection of target firms. Since selective targeting is a key aspect of the activist investment strategy, the relevant research question in our context is whether hedge fund intervention from shareholder campaigns to proxy contests impacts the targets' innovation strategies beyond what would have materialized had the hedge funds accumulated the same ownership in the companies but as passive investors. In contrast to most research that accomplishes identification via exogenous shocks in the treatment status, we do not take a stand on what would have happened had hedge funds been matched randomly to their targets. We conduct three tests to disentangle the effects of intervention from mere stock picking. 
The first test addresses the specific alternative hypothesis that hedge funds select companies in which management would have implemented changes to innovation even without direct or indirect pressure from the activist. We therefore focus on the subsample of openly confrontational events in which the hostile nature of hedge fund activism evidently reflects management's resistance. We find that the subsample of hostile engagements shows qualitatively similar changes compared with the rest of the activist interventions. The second test targets the counterfactual theory that hedge funds engage in stock picking rather than adding value through intervention. A legal feature in ownership disclosure offers a source of identification. Specifically, we measure the performance of firms for which hedge fund ownership (and hence stock picking) remained constant, but the fund switched from a 13G (passive ownership) to a 13D (activist) filing status. ${ }^{6}$ The significant improvement by target firms after the hedge funds' decision to switch their filing relative to the firms for which the hedge funds maintained a $13 \mathrm{G}$ filing suggests that the changes in innovation among target firms reflect an incremental effect of intervention over stock picking. The third test is based on stock market price reactions to patent grant announcements. We estimate the incremental value of patents filed prior to the arrival of the activists but granted shortly after the intervention relative to those granted shortly beforehand. The two sets of patents are comparable because they were both filed pre-intervention due to the long delay between filing and granting of about two to three years. We document a significant increase of 31 to 45 basis points in abnormal stock return during the five-day window centered around the patent grant day, suggesting the pre-existing innovation outputs become more valuable because they are better utilized and allocated under the "new" regime.

Our study presents a more nuanced picture than a straight answer as to whether hedge fund activism or pressure from the stock market in general, encourages or impedes corporate innovation. While inputs to innovation measured by $R \& D$ expenditures decline post hedge fund intervention, we find that this

\footnotetext{
${ }^{6}$ A shareholder who acquires more than $5 \%$ beneficial ownership is required to disclose in the Schedule 13D within 10 days of crossing 5\% if it intends to influence control. If the investment intention is purely passive, the disclosure requirement is a less stringent $13 \mathrm{G}$ form. Section 5 provides a more detailed discussion of these filing requirements. Several recent studies have applied this identification scheme in similar settings, including Brav, Jiang, and Kim (2015b) and Aslan and Kumar (2016).
} 
reflects the broader decline in the size of the target firm. Importantly, the output from innovation, patent quality and quantity, tend to improve. These improvements are concentrated in areas that are central to the firms' business and technological expertise. Thus, our evidence suggests that firms become "leaner" but not "weaker" subsequent to hedge fund interventions. Moreover, the efficiency gains also emanate from the extensive margin through the redeployment of innovative assets (patents or innovators). This pattern parallels activist hedge funds' role in improving the productivity of physical assets through reallocation (i.e., plant sales and other strategic changes in the allocation of firm resources) as documented by Brav, Jiang, and Kim (2015b). Activists are effectively redrawing the target firm's boundaries via the refocusing and leveraging of core competency.

Our study contributes to the growing literature exploring how financial markets and corporate governance affect corporate innovation, where earlier studies examined the effects from firms' public offering decisions (Bernstein (2015)), anti-takeover provisions (Chemmanur and Tian (2013)), and institutional ownership (Aghion, Van Reenen, and Zingales (2013)). We relate innovation to an increasingly important new form of market-based corporate governance, hedge fund activism, to inform the current debate as to whether the pressure from empowered shareholders impacts the long-term viability of public companies. Closest to our paper is Seru (2014), who argues that firm boundaries matter for innovation by showing that firms acquired in diversifying mergers produce fewer and less novel patents afterwards and that this is driven by a decline in inventors' productivity rather than inventor exits. Our study illustrates in a different setting how the redrawing of firm boundaries, by the activists rather than via a change in control, leads to higher innovative efficiency. Our paper is also related to recent work on the effect of private equity/venture capital (PE/VC) involvement with innovation (Lerner, Sorensen, and Stromberg (2011)). Activist hedge funds are, however, critically different from PE/VC in that their primary role is not financing, but rather as vigilant external monitors without taking control. For this reason, activist hedge funds do not target fledging enterprises that need nurturing; instead they seek more mature firms that are prone to the agency problems of free cash flows described in Jensen (1986). We 
therefore view the two bodies of work as complementary in studying innovation in different stages of the firms' life cycle.

\section{Data and Sample Overview}

\subsection{Data sources}

\subsubsection{Innovation}

We adopt two sets of measures to capture both the input to and the output from the innovation process. The input measure is the level of annual $R \& D$ expenditures from Compustat. While this measure is simple and intuitive, the use of $R \& D$ suffers from several limitations: It is incomplete with more than $50 \%$ of the observations missing in Compustat; it captures only one particular observable and quantifiable input; and it is sensitive to accounting discretion regarding whether it should be capitalized or expensed (Acharya and Subramanian (2009)). ${ }^{7}$

The second measure, which we use as a proxy for output from innovation, is a firm's patenting activity, reflecting the successful use of observable and unobservable innovation inputs. The use of patenting activity has become a standard practice in the literature (e.g., Acharya and Subramanian (2009); Aghion, Van Reenen, and Zingales, (2013); Seru (2014)). ${ }^{8}$ We access the National Bureau of Economic Research (NBER) patent database as of 2013 to obtain annual patent-level information from 1991 to 2006. The relevant information includes information on the patent assignee (the entity, such as the firm, which owns the patent), the number of citations received by the patent, the technology class of the patent, and the patent's application and grant year. Bhaven Sampat's United States Patent and Trademark Office (USPTO) patent and citation data allows us to extend the NBER patent database up to $2010 .{ }^{9}$

While the use of the NBER patent database facilitates the measurement of general patenting activities, we are also interested in data that would allow us to measure the reallocation of both patents

\footnotetext{
${ }^{7} \mathrm{We}$ winsorize firms' financial data at the $1 \%$ extremes. Following the norm in the existing literature, we impute missing values of $R \& D$ as zero if the same firm reports $R \& D$ expenditures for at least one other year during the sample period. Otherwise, we treat the observation as missing.

${ }^{8}$ Although there have long been criticisms of the patenting measure under certain circumstances, including defensive patenting, patent thickets, and potential abuses by patent trolls (e.g., Shapiro (2001) and Bessen, Ford, and Meurer (2011)), the consensus in the literature appears to be that it remains a reasonable proxy for innovation.

${ }^{9}$ Available at: http://thedata.harvard.edu/dvn/dv/boffindata.
} 
and human capital subsequent to the arrival of hedge fund activists. We track inventor mobility using the Harvard Business School (HBS) patent and inventor database..$^{10}$ Covering the period from 1991 to 2010, this database provides the names of the inventors (the individuals who receive credit for producing a patent) and their affiliations with the assignees, thus tracking the mobility of individual inventors (see Lai, et al. (2013) for details).

We create a database of patent transactions based on the USPTO patent assignment files, hosted by Google Patents. ${ }^{11}$ This database provides useful information for the purpose of identifying patent transactions: the assignment date, the participating parties, including the assignee (the "buyer") and the assignor (the "seller") in a transaction, and comments on the reason for the assignment. We merge the raw assignment data with the USPTO patent database so as to gather additional information on the original assignees and patent technology classes, and with the HBS inventor database. We then follow a procedure, similar to that in Serrano (2010), Akcigit, Celik, and Greenwood (2015), and Ma (2015), in which we identify patent transactions from all patent reassignment records. We do not include reassignments associated with cases involving a patent transfer from an inventor to her employer, or that between two subsidiaries of a firm. Appendix A-3 provides a more detailed description of the data and methodology.

\subsubsection{Hedge fund activism}

The sample of hedge fund activism events, covering the period from 1994-2007, is an extension of the sample studied in Brav, Jiang, Partnoy, and Thomas (2008), which describes the details of the sample selection criteria. The events are identified mainly through Schedule 13D filings submitted to the Securities and Exchange Commission (SEC) (accessible via the EDGAR system). These filings are required for any investor who owns more than 5\% of any class of publicly traded securities of a company and who intends to influence corporate policy or control. We then supplement this sample using news searches for activists who own between $2 \%$ and $5 \%$ of shares at mid- to large-cap companies (companies with more than $\$ 1$ billion in market capitalization).

\footnotetext{
${ }^{10}$ Available at: http://dvn.iq.harvard.edu/dvn/dv/patent.

${ }^{11}$ The data are accessible via bulk downloading of text files. See http://www.google.com/googlebooks/usptopatents.html.
} 
Panel A of Table 1 reports the number of hedge fund activism events for each year from 1994 to 2007. The number of events increased over our sample period, peaking in 2007, but with some evidence of pro-cyclicality. Given the goals of this study, we limit the sample to potentially "innovative firms," defined in two ways. The first definition requires that the firm file at least one patent in any year prior to hedge fund intervention and with at least one positive R\&D expenditure within the five-year window prior to the intervention. The second definition narrows the time window and requires that the firm filed at least one patent in the three-year period prior to hedge fund intervention (i.e., $t-3$ to $t-1$ ) and the same criterion for R\&D. Table 1 Panel A indicates that about $30 \%$ of the hedge fund targets are innovative firms according to the first definition (columns 2 and 3) and $24 \%$ based on the more stringent second definition (columns 4 and 5). On average, innovative target firms own about 20 patents in the year of the hedge fund intervention. Panel $\mathrm{B}$ of Table 1 shows the number of hedge fund activism events and the representation of innovative firms for each of the Fama-French 12 industries. ${ }^{12}$ Naturally, the sample is over-represented in the most innovation-intensive industries, such as high tech (20\% of the sample), healthcare (11\% of the sample), and manufacturing ( $9 \%$ of the sample).

[Insert Table 1 here.]

\subsection{Main innovation variables}

\subsubsection{Patent quantity and quality}

Patents are the most natural and measurable output from the process of innovation. Patent quantity can be simply measured as the number of patent applications filed by a firm in a given year that are eventually granted. The choice of application (rather than grant) year better captures the actual time of innovation (Griliches, Pakes, and Hall (1988)).

There are several frequently used measures for patent quality. Most notably, patent quality is measured using the number of subsequent lifetime citations, the patent's originality, and the patent's generality. The first, the number of citations each patent receives in subsequent years, differentiates patents based on their impact. Although there are two truncation problems with this measure, the

\footnotetext{
${ }^{12}$ Detailed industry definitions can be downloaded from Ken French's Data Library at: http://mba.tuck.dartmouth.edu/pages/faculty/ken.french/data_library.html,
} 
mitigating solutions are well developed in the literature. The first problem arises because patents appear in the database only after they are granted, and there is a significant lag (of about two years, on average) between the application and the eventual grant date. As a result, patent applications filed toward the end of our sample period are underrepresented. Hall, Jaffe, and Trajtenberg's $(2001,2005)$ "weight factors" have become the standard procedure to adjust the empirical distribution of granted patents. The second problem arises because of sample-end censoring (in our study, the sample ends in 2010). The same references suggest that we correct the bias by dividing the observed citation counts by the fraction of predicted lifetime citations based on a citation-lag distribution. The resulting patent counts and citations are both right skewed, justifying the log-transformation of the variables in the regressions. ${ }^{13}$

It is worth noting that firm attrition does not compromise the NBER Patent and Citation database since information is recorded at the patent level. As long as a patent is eventually granted it is properly attributed to the assignee at the time of application even if the firm has since been acquired or filed for bankruptcy, and citations are properly accrued to the patent.

Second, Hall, Jaffe, and Trajtenberg (2001) develop two measures for the quality and importance of patents beyond a simple citation count. Patents that cite a wider array of technology classes of patents are viewed as having greater originality, while patents that are cited by a wider array of patent technology classes are viewed as having greater generality. More specifically, a patent's originality score is one minus the Herfindahl index of the three-digit technology class distribution of all the patents it cites. A patent's generality score is one minus the Herfindahl Index of the three-digit technology class distribution of all the patents that cite it. We follow Kerr and Nanda's (2015) recommendation for the reporting of originality and generality by tracing these metrics' evolution in the years prior and subsequent to the arrival of activists.

\footnotetext{
${ }^{13}$ Dass, Nanda, and Xiao (2015) have recently questioned the efficacy of the bias adjustments proposed by Hall, Jaffe, and Trajtenberg $(2001,2005)$, raising the concern that the magnitude of the bias is correlated with firm attributes. We show in the online appendix that the results presented later in Section 3 are not sensitive to this concern by repeating the analysis using activism events that occurred over the first part of our sample period, 19942002 .
} 
Last, we follow Kogan, Papanikolaou, Seru and Stoffman (2015) by measuring the quality of innovation using the market value of a new patent as implied by the market responses to the patent approval. A patent's value is measured as the target firm stock return in excess of the market over the three-day window around the date of patent approval multiplied by the firm's market capitalization on the day prior to the announcement.

\subsubsection{Innovation strategy}

Turning from patents to firms, we employ three variables to describe a firm's innovation strategy. The first variable, proposed by Sorensen and Stuart (2000) and further extended by Custódio, Ferreira, and Matos (2013), measures a firm's innovation diversity. This diversity measure equals one minus the Herfindahl index of the number of new patents across different technological classes, measured over the most recent three years. A high diversity value indicates higher diversification, or lower concentration of patenting activities, across different technology classes.

The second variable, proposed by Manso (2011) and further extended by Almeida, Hsu, and Li (2013) and Custódio, Ferreira and Matos (2013), summarizes the innovation strategy by the extent to which the new patents are exploratory or exploitative. A patent is considered exploitative if at least $80 \%$ of its citations are based on the existing knowledge of the firm, whereas a patent is exploratory if at least $80 \%$ of its citations are based on new knowledge. Existing knowledge includes all the patents that the firm invented and all the patents that were cited by the firm's patents filed over the past five years. The two categories are not exhaustive. Aggregated at the firm-year level, the percentage of exploitative/exploratory new patents is indicative of whether a firm's innovative strategy relies heavily on existing knowledge (e.g., incremental relative to existing patents) or focuses on exploring new technologies.

Finally, we adopt the methodology developed in Akcigit et al. (2013) to measure the distance between a given patent and the firm's overall patent portfolio. Akcigit et al. (2013) first measure the distance between any two technology classes as the ratio of the number of all patents that simultaneously cite patents from both technology classes to the number of all patents that cite at least one patent from 
either of these technology classes, or both. Next, they measure a patent's distance from the firm's overall patent portfolio as the weighted average of the patent's distance to each of the other patents that firm owns using these technology class distance measures. Appendix A-2 provides the precise derivation of this measure.

\subsection{Sample overview}

We merge all the databases described in the previous sections to form the master database. Our main analyses are conducted on the pooled sample of hedge fund target firms and firms matched by propensity scores. We match each firm targeted by a hedge fund in year $t$ with a non-target firm from the same year and 2-digit Standard Industrial Classification (SIC) industry code that has the closest propensity score, estimated using log firm size, market-to-book ratio, and return on assets (ROA) measured at $t-1$, and the change in the target firm ROA measured between years $t-3$ and $t-1$ to capture pre-event trends of deterioration in the operating performance of target firms. Our results are both qualitatively and quantitatively similar when we add more characteristics to the calculation of propensity scores and, as will be shown later, the target and control firms are statistically indistinguishable along a number of unmatched dimensions.

Table 2 reports summary statistics (at the event year) comparing the characteristics of the hedge fund target firms with those of the matched firms. As discussed in Section 2.1.2, the focus of this study centers on innovative firms, that is, firms filing at least one patent in any year (or, depending on the definition of an innovative firm, within three years) prior to the event year. Table 2 presents the mean, standard deviation, $25^{\text {th }}, 50^{\text {th }}$ and $75^{\text {th }}$ percentile for each of the firm characteristics. The last two columns report the differences and the $t$-statistics testing the equality of means of the two samples. The target and matched firms are indistinguishable for multiple characteristics, such as size, market to book ratio, and ROA, although hedge fund targets have marginally higher leverage.

Interestingly, the two samples are similar in both innovation inputs and outputs in the year of the intervention, despite the fact that these characteristics are not part of the matching criteria. For example, both invest an equivalent of $7 \%$ of their total assets in R\&D during the event year. Target firms (control 
firms) file 1.27 (1.37) patents in the event year, and each patent receives a total of 2.22 (2.20) citations in all future years. Moreover, target firms demonstrate slightly lower, but still similar, values for most of the variables characterizing patenting characteristics and innovation strategies, such as patent originality and generality, portfolio diversity, patenting distance, and the extent to which the overall strategy is explorative or exploitative. ${ }^{14}$

\section{[Insert Table 2 here.]}

\section{Hedge Fund Activism and Corporate Innovation}

Our empirical analyses begin with an examination of the relationship between hedge fund activism and corporate innovation. The sample consists of firm-year level observations from 1991 to 2010, in which firms are limited to hedge fund targets and their matched firms. The event year for a target firm also becomes the "pseudo-event" year for its matched firm. The sample is further restricted to observations beginning five years prior to the event year (pseudo-event year) through five years afterwards.

We adopt the following standard difference-in-differences (DiD) regression framework:

$$
\text { Innovation }_{i, t}=\beta_{1} I\left(\text { Target }_{i}\right) \times I\left(\text { Post }_{i, t}\right)+\beta_{2} I\left(\text { Post }_{i, t}\right)+\gamma \text { Control }_{i, t}+\alpha_{t}+\alpha_{i}+\varepsilon_{i, t}
$$

In equation (1), $i$ and $t$ are subscripts for firm and year, respectively. The dependent variable Innovation $_{i, t}$ is equal to one of the innovation input/output proxies described in Section 2.2. I(Target $\left.i\right)$ is a dummy variable equal to one if firm $i$ is the target of hedge fund activism. I(Post $\left.t_{i, t}\right)$ is a dummy variable equal to one if the firm-year $(i, t)$ observation is within $[t+1, t+5]$ years of an activism event (for target firms) or a pseudo-event year (for match firms). The results are robust if we instead use the three-year period following the event. Finally, $\alpha_{t}$ and $\alpha_{i}$ represent year and firm fixed effects, and Control $l_{i, t}$ is a vector of control variables, including market capitalization and firm age (both in logarithmic terms). The coefficient of interest is thus $\beta_{1}$, the coefficient associated with the interaction term $I\left(\right.$ Target $\left._{i}\right) \cdot I\left(\right.$ Post $\left._{i, t}\right)$,

\footnotetext{
${ }^{14}$ Since targets of hedge fund activists tend to experience a high rate of attrition from Compustat (see Brav, Jiang, Kim (2015a)) we also compare the attrition rate of the innovative target firms to that of the propensity score matched sample. The evidence, presented in the online appendix, is that the attrition rates are essentially identical, with $66.7 \%$ $(64.6 \%)$ of the target (matched) firms surviving through five years post event.
} 
which indicates the differential change in innovation inputs/outputs in target firms post hedge fund intervention, compared to those for matched firms. Table 3 reports the results of regression (1).

[Insert Table 3 here.]

Columns (1) and (2) of Table 3 Panel A provide results in which we use two measures of inputs to innovation. The first dependent variable is the annual $R \& D$ expenditures scaled by firm assets, measured in percentage points, and the second is the level of annual $R \& D$ expenditures, measured in millions of dollars. The coefficients associated with $I\left(\right.$ Target $\left._{i}\right) \cdot I\left(\right.$ Post $\left._{i, t}\right)$ are both negative, but only significant in the second specification, and show that on average target firms' total R\&D expenditures decrease by $\$ 11$ million post intervention (about $20 \%$ of the average $R \& D$ in our sample) relative to the changes incurred by matched firms. Panel A of Figure 1 shows that there is clearly no pre-trend in R\&D/Assets ratio. The finding that $R \& D$ expenditures decrease significantly even though the $R \& D /$ Assets ratio remains roughly flat is consistent with the fact that, post activism, $R \& D$ expenditures scale back roughly in proportion to the reduction in the target firms' assets due to both a drop in capital expenditures and an increasing rate of asset spinoffs/sales (Brav, Jiang, and Kim (2015a)).

Column (3) examines the number of new patents. The dependent variable is the logarithm of new patents (plus one). Hence, the estimated coefficients should be interpreted in semi-elasticity terms. Subsequent to the arrival of hedge fund activists target firms file for about $15.1 \%$ more patent applications compared to the matched firms, controlling for both firm and time fixed effects. The effect is statistically significant and economically sizable, especially when considering that the mean of the dependent variable $\ln ($ number of new patents +1 ) is 0.50 (see Table 2). Needless to say, the quality of patents is as important as the quantity. The remaining four columns in Panel A provide evidence on changes in patent quality using several commonly used proxies for quality.

In column (4), the dependent variable is the logarithm of the average number of citations per patent (plus one). The coefficient on $I\left(\right.$ Target $\left._{i}\right) \cdot I\left(\right.$ Post $\left._{i, t}\right)$ is statistically significant, indicating that patents filed post intervention collect $15.5 \%$ more citations, on average, than patents filed by matched firms during the same period. Columns (5) and (6) show that the originality and generality scores of patents filed by target 
firms post-event also increase relative to matched firms, although only the coefficient estimate associated with originality is significant. Finally, column (7) provides evidence on changes in patent quality post activism measured by the market value of new patents as implied by market responses to patent approvals (see Kogan et al. (2015)). Patent value is measured by the target firm stock return in excess of the market over the three-day window around the date of patent approval multiplied by the firm's market capitalization on the day prior to the announcement. The dependent variable, Yearly Innovation Value, aggregates the sum of stock market reactions to all patents applied for in a given year. On average, target firms see an increase of $\$ 12$ million in their market capitalization relative to the matched controls in the post intervention period, although this estimate is only significant at the $10 \%$ level. ${ }^{15,16}$

Panel B explores specific subsamples that are particularly informative about the nature of the improvement. Column (1) constrains the previous analysis on citations to new patents to the subset of new patents that rank as the top $20 \%$ most cited patents produced by firm $i$ in year $t$ to assess the impact of intervention on the presumably most valuable innovative assets. The positive and significant slope on the interaction term indicates that the shift in quality documented in Panel A encompasses the top end of the quality spectrum.

Next, we examine whether the main results hold in industries with short lags between the inputs (e.g., $\mathrm{R} \& \mathrm{D}$ and strategic planning) and the realization of innovation (e.g., patents). Evidence for an improvement in patenting activities in industries with short lags would serve to alleviate the concern that that hedge funds select firms with more patents in the pipeline prior to the intervention. To calibrate the length of the time lag, we follow Hall, Griliches, and Hausman (1986) and regress, for each industry, the number of new patents on R\&D expenditures in the current and each of the past five years at the firm-

\footnotetext{
${ }^{15}$ The online appendix provides two additional robustness checks. First, we restrict the definition of "innovative" target firms to those that have at least five patents prior to the year of the intervention and find qualitatively similar evidence. Specifically, R\&D expenditures decrease significantly by approximately $\$ 15.6$ million, but the R\&D/Assets ratio remains essentially unchanged. Target firms file for about $16 \%$ more patent applications compared to the matched firms, and patents filed post intervention receive $15.5 \%$ more citations than patents filed by matched firms. Second, we adopt a negative binomial specification instead of that in equation (1), including year and firm fixed effects, and find a similar strong positive estimate on the interaction term $\left(\right.$ Target $\left._{i}\right) \cdot I\left(\right.$ Post $\left._{i, t}\right)$.

${ }^{16}$ Lerner and Seru (2015) suggest that researchers confirm that their analyses are robust to several potential biases, which may arise form the use of the patent data. They propose a checklist comprised of several questions that we present in Appendix A-4 along with our responses to these questions.
} 
year level. Confirming the earlier study, we find that only the following four industries have coefficients that are significant beyond the one-year lag: chemical, healthcare, medical equipment, and drug (CHMD). We thus analyze the number of patents and average citations separately for the CHMD subset (industries with the R\&D-to-patent lag significantly longer than one year) and non-CHMD industries (those industries with shorter lags).

The results are reported in panel B, columns (2) through (5). We find that subsequent to the arrival of hedge fund activists, target firms in non-CHMD (CHMD) industries file about $12.9 \%$ (23.1\%) more patent applications than matched firms controlling for both firm and time fixed effects. We also observe that subsequent lifetime citations to these new patents increase for both subsamples although the increase is significant only for the non-CHMD industries. The improvement in innovation at non-CHMD industries coupled with the evidence, presented later in this section, that the increase in target firms' innovation is significant beginning only in the second year after the arrival of activists, help to mitigate the concern that the results reported in Panel A of Table 3 are driven by activists' ability to select target firms that are about to file for new patents. We revisit the issue of selection and causality more formally in Section 5.

Confirming that the results are not driven by different pre-event trends between targets and their matched controls, Figure 1 displays the changes in the input and output from innovation at target firms relative to that of controls by plotting the differences in pre- and post-trends in $R \& D / A s s e t s$, the number of new patents, and associated citations between targets and controls. The coefficients, $\beta_{-3}, \ldots, \beta_{5}$, are the slopes on the interactions of yearly dummies extending from three years prior to the activism event year through five years afterwards and an indicator of being targeted by hedge funds. The coefficients are estimated from the following specification in equation (2):

Innovation $_{i, t}=\sum_{k=-3}^{+5} \lambda_{k} d[t+k]_{i, t}+\sum_{k=-3}^{+5} \beta_{k}\left\{d[t+k]_{i, t} \times I\left(\right.\right.$ Target $\left.\left._{i}\right)\right\}+\gamma \cdot$ Control $_{i, t}+\alpha_{i}+\alpha_{t}+\varepsilon_{i, t}$,

The dummy variables $d[t-3], \ldots, d[t+5]$ correspond to firm-year observations from three years before to five years after the (pseudo-) event year, and zero otherwise. I( Target $\left._{i}\right)$ is a dummy variable equal to 
one if the firm is a hedge fund target or a matched control firm. As in equation (1), the control variables include the natural logarithms of firm market capitalization and firm age. We also include firm and year fixed effects. Panel A plots the estimates of the difference between targets and controls in R\&D/Assets. Panel B plots the estimates of the difference between targets and controls in the quantity of innovation as measured by the logarithm of the number of patents filed by firm $i$ in year $t$. Panel $\mathrm{C}$ plots the estimates of the difference between targets and controls in the quality of innovation as measured by the logarithm of the average citations received by patents filed by the firm in year $t$.

[Insert Figure 1 here.]

The three propensity score matching plots in Figure 1 show that the difference is negligible between target and control firms in R\&D intensity, the number of new patents, and associated citations in the three years prior to the arrival of activist hedge funds. The parallel trend in the R\&D input continues into the post-intervention years, but divergence emerges within one to two years for the output measures, and the departure in the number of patents (citations per patent) is statistically significant in the second year post intervention. The length of time it takes for external shareholder monitoring to manifest in innovation activities is plausible, and is on par with the finding of Lerner, Sorensen, and Stromberg (2011). Combining the evidence on both inputs and outputs, Table 3 and Figure 1 suggest that target firms become more efficient in the process of innovation.

The positive impact on innovation offers one explanation for the widely documented positive stock market response to the announcement of hedge fund activism, with no evidence of reversal in the longer term. In the online appendix, we conduct an abnormal return analysis, following the approach in Brav et al. (2008), on the subsample of innovative targets, and make two inferences. First, the short run average abnormal return for this subsample is $6 \%$ during the twenty-day window around the announcement, similar to the full sample of targets. Second, the short-term average abnormal return does not reverse in the ensuing three to five years. The alphas from equal and value weight calendar time portfolios of innovative targets using both the CAPM and Fama-French four-factor models are all positive although insignificant. 


\section{Hedge Fund Activism and Innovation: Potential Channels}

The challenge to identify the channels through which activism improves innovation efficiency is that most activist shareholders are not perceived to be experts in the target firms' technological expertise, and activist proposals do not commonly state as a goal the reformulation of the target firm's innovation (in either the Schedule 13D filing or in accompanying news releases). The main contribution of this study is thus to enhance our understanding of the possible channels to shed light on the causal impact of hedge fund activists.

The body of literature on hedge fund activism reviewed in Brav, Jiang, and Kim (2015a) provides a coherent pattern: hedge fund activists tend to make their targets leaner and more focused by trimming off unproductive and peripheral assets, unbundling business segments, and opposing diversifying acquisitions. As such, asset redeployment plays an important role in the observed improvement in operating performance. We hypothesize that in general the gain in innovation efficiency may be a direct by-product of the redrawing of the firm boundaries mostly via selective asset sales and matching of the currently unproductive assets to more suitable owners. Other changes, such as improved corporate governance and more performance-oriented incentives for management, could also impact target firms' innovation as managers are held more accountable for return on R\&D investments and performance.

\subsection{Cross-sectional heterogeneity: Diversity of innovation}

Several recent studies have analyzed the effect of diversity on innovation following the literature on the scope of operation and the value of the firm (see the survey by Stein (2003)). For example, Seru (2014) shows that although target firms in diversifying mergers produce fewer and less novel patents after such mergers, firms overcome this reduction by increasing innovation outside the firm's core expertise using strategic alliances and joint ventures. In a related setting, Bena and Li (2014) show that firms are more

likely to acquire technologically similar targets and synergies in these types of mergers are associated with larger benefits.

Our test is motivated by Akcigit et al. (2013), who show that a patent contributes more to a firm's value if the patent is closer to the firm's technological expertise and core business area. Given that one 
important theme of hedge fund activism is refocusing, we expect that firms with a more diverse portfolio of innovation at the outset will benefit more from the strategic changes brought about by activists. An empirical assessment of such cross-sectional heterogeneity requires that we re-run equation (1) with the addition of two interaction terms, $I\left(\operatorname{HighDiv}_{i}\right)$ and $I\left(\operatorname{LowDiv}_{i}\right)$, which are disjoint dummy variables indicating whether a firm's patent diversity during the event (or pseudo-event) year is above or below the median. That is, the regression specification is now:

$$
\begin{aligned}
\text { Innovation }_{i, t}= & I\left(\text { HighDiv }_{i}\right) \times\left[\beta_{1} I\left(\text { Target }_{i}\right) \times I\left(\text { Post }_{i, t}\right)+\beta_{2} I\left(\text { Post }_{i, t}\right)\right] \\
& +I\left(\text { LowDiv }_{i}\right) \times\left[\beta_{3} I\left(\text { Target }_{i}\right) \times I\left(\text { Post }_{i, t}\right)+\beta_{4} I\left(\text { Post }_{i, t}\right)\right] \\
& +\gamma \text { Control }_{i, t}+\alpha_{t}+\alpha_{i}+\varepsilon_{i, t}
\end{aligned}
$$

The two sets of coefficients $\left\{\beta_{1}, \beta_{2}\right\}$ and $\left\{\beta_{3}, \beta_{4}\right\}$ are reported in Table 4 . Of interest is the test for the equality: $\beta_{1}-\beta_{3}=0$, or a triple difference for the differential improvement of firms with diverse versus focused patent portfolios post event.

\section{[Insert Table 4 here.]}

With regard to the number of new patent applications, columns (1) and (2) in Panel A present positive estimates of both $\beta_{1}$ and $\beta_{3}$, although only $\beta_{1}$ (for the high diversity subsample) is highly significant, indicating a positive post-intervention effect for the high diversity subsample. Importantly, the estimate of $\beta_{1}$ is 0.232 , about 4 times larger than $\beta_{3}$ (for the low diversity sample), and the F-test in column (3) shows that the difference is statistically significant. The same pattern holds when we look at patent citations (columns (4) and (5)). The difference is positive but insignificant. The message from Panel A is that target firms that had a diverse set of patents prior to the intervention generate more patents and citations per patents within the five-year window after the arrival of activists. This result is interesting when corroborated with the evidence shown later (Section 4.3) that intervention is associated with the selling of patents that are distant from the target firms' main technological expertise.

Panel B presents further evidence that the increase in patents and citations is driven by target firms' innovative activities within their core technological expertise by examining the dynamics of output from innovation in key and non-key technology classes. A technology class is key (non-key) to a firm if the 
highest number (lowest number) of the firm's patent stock is assigned to that class. In columns (1) and (2), the dependent variables are constructed by counting the number and average citations of new patents in the technology class that is key to a firm. In columns (5) and (6) the dependent variables are constructed by counting the number and average citations of the new patents not in the firm's key technology class. As seen from the coefficient on the interaction term $\left(\right.$ Target $\left._{i}\right) \cdot I\left(\right.$ Post $\left._{i, t}\right)$, patent counts and citations increase significantly only in key technology classes (0.194 and 0.182 in columns (1) and (2)). There is no evident increase in either patents or citations in non-key technology classes as shown in columns (5) and (6). The online appendix provides qualitatively similar results when we rank technology classes by the number of the firm's patents assigned to each class and define the top three as key technology classes and the bottom three classes as non-key.

The evidence so far suggests that the change in innovative activities originates from target firms that started with a diverse set of patents and, after the arrival of activists, focused their innovative activities on their core technological expertise. But two questions arise: Do these changes simply reflect added efforts to innovate in the well-trodden areas in which the target had been innovating? Are these genuinely creative attempts to move beyond the past innovations while remaining within the same technological class? To address this set of questions we follow the literature and focus on the intensity of exploration, proxied by the variable Explorative, which measures the intensity with which a firm innovates, based on new rather than existing knowledge. A patent is explorative if at least $80 \%$ of its citations refer to new knowledge (all patents that the firm did not invent and all patents not cited by the firm's patents filed over the past five years). We then compute the percentage of explorative patents filed in a given year by the firm. This firm-year level variable is separately constructed for patents from the key technology class (column 3) or the technology class defined as non-key (column 7). We also measure the intensity with which a firm innovates based on existing knowledge using the variable Exploitative. A patent is classified as exploitative if at least $80 \%$ of its citations refer to existing knowledge, which includes all the patents that the firm invented and all the patents that were cited by the firm's patents filed over the past five years. We then compute the percentage of exploitative patents filed in a given year by the firm. 
Panel B of Table 4 indicates that activists bring changes only in explorative strategies in technological areas that are central to the target firm, where the percentage of explorative patents in target firms' key technology classes increase by about $4 \%$ (column (3), significant at the $1 \%$ level) relative to the matched firms post-intervention. Changes in exploitative patents in the key classes and changes in both types of patents in the non-key classes are all far from being significant.

Overall, the evidence is consistent with the view that post-intervention the improvement in innovation productivity is more pronounced among firms that started with a more dispersed innovation portfolio but then refocus innovative activities within the core technological capabilities while seeking to move beyond knowledge they generated in the past. We now turn to the more precise examination of the characteristics of patents that are reallocated and whether these patents are put to better use once they are sold by the target firms.

\subsection{Reallocation of patents}

\subsubsection{Example of intervention seeking the reallocation of patents: Starboard Value and AOL, Inc.}

On February 16, 2012, Starboard Value LP filed a Schedule 13D with the SEC indicating that it owned $5.1 \%$ of AOL, Inc. The filing included a letter that the fund had sent to the CEO and Chairman, Tim Armstrong two months earlier that reviewed of each of the firm's business units (Access, Search, Advertising Network, and Display) based on publicly available information. Starboard argued that the management and the board needed to consider various ways to enhance AOL's shareholder value, most importantly, to address the "valuation discrepancy...due to the Company's massive operating losses in its Display business, as well as continued concern over further acquisitions and investments into moneylosing growth initiatives like Patch." The letter concludes with a request for direct engagement with the board in order to discuss ways to find strategic alternatives that would stabilize the company and improve its operating performance and valuation.

On February 27, 2012 Starboard filed an amendment to its Schedule 13D with a second letter explicitly focusing on AOL's portfolio of intellectual property. The letter states: 
“...in addition to the valuable assets highlighted in our December Letter, AOL owns a robust portfolio of extremely valuable and foundational intellectual property that has gone unrecognized and underutilized. This portfolio of more than 800 patents broadly covers internet technologies with focus in areas such as secure data transit and ecommerce, travel navigation and turn-by-turn directions, search-related online advertising, real-time shopping, and shopping wish list, among many others."

The hedge fund proceeded to argue that the intellectual property was underutilized by pointing that other companies were likely infringing on AOL's patents. As a result, the fund projected that the portfolio of patents would generate more than $\$ 1$ billion of licensing income if properly managed. The fund also cautioned that the tax liability associated with the sale of the patents should be considered, and therefore argued for the divestiture of other high cost basis assets. To facilitate the changes, the fund proposed five of its own directors should be elected to the board during the 2012 annual meeting.

Soon thereafter, AOL retained Evercore Partners as its financial adviser, and, in early April 2012, the company announced that it would sell more than 800 patents and related patent applications to Microsoft for $\$ 1.06$ billion. The company agreed to grant Microsoft a non-exclusive license to the more than 300 patents and patent applications the company chose to retain. The agreement was reached after an open auction with multiple bids by interested companies. AOL share prices increased roughly $40 \%$ over the three months following the sale of the patents. ${ }^{17}$

\subsubsection{Patent transactions and subsequent performance}

Motivated by the case described above and our previous analyses, this section proceeds to study the reallocation of patents owned by target firms (and their matched firms) through patent transactions with an emphasis on the sale of patents, and the resulting changes in patent portfolios and innovation efficiency. We begin with the same specification as in equation (1), but replace the dependent variable with patent transactions, measured as the annual number of patents purchased (sold) by a firm scaled by the total number of patents owned by the firm at the beginning of the year. The construction of the

${ }^{17}$ For more details, see, "AOL Jumps After \$1.06 Billion Patent Accord with Microsoft," by Danielle Kucera, published on www.Bloomberg.com, April 10, 2012. 
dependent variable necessarily constrains the relevant sample to firm-year observations in which firms own at least one patent during the event year. We include year fixed effects in all specifications and either industry or firm fixed effects. Results are reported in Panel A of Table 5.

[Insert Table 5 here.]

The coefficient on the interaction term, $I\left(\right.$ Target $\left._{i}\right) \cdot I\left(\right.$ Post $\left._{i, t}\right)$, in columns (1) and (2) of Panel A, reveals that target firms increase the number of patent sales post intervention at an annual rate of approximately $0.64 \%$, as compared to the unconditional annual sale rate of $0.8 \%$. As to patent purchases, the same coefficient in columns (3) and (4) is insignificant with either industry or firm fixed effects. The question that naturally follows is, then, which characteristics of patents, especially with regard to their relation to the core competence of the firm, are associated with a higher propensity of being sold? Panel $\mathrm{B}$ of Table 5 offers an answer. Here the sample consists of patent-firm-year $(j, i, t)$ level observations,

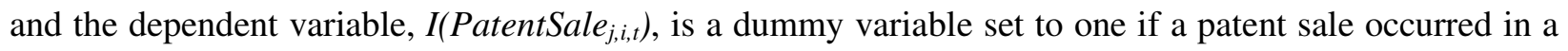
given year. The key independent variable Distance $_{j, i, t}$ developed in Akcigit et al. (2013) measures the distance between a given patent $j$ and firm $i$ 's overall patent portfolio in a year. The two columns vary in the value $(0.33$ and 0.66$)$ of the weighting parameter $l$ used in constructing Distance $_{j, i, t}$. Appendix A-2 contains a more detailed description of this variable and the parameter $l$. Before $i, t$ is a time dummy variable equal to one if year $t$ falls into the [t-3, t-1] range relative to the event year, and similarly, After $r_{i, t}$ is a dummy variable equal to one if year $t$ falls into the $[\mathrm{t}, \mathrm{t}+3]$ range. Both Before $_{i, t}$ and $A f t e r_{i, t}$ are coded as zero for all observations belonging to the matched firms. All specifications include year and patent vintage fixed effects. We adopt the linear probability model in order to accommodate the highdimensional fixed effect setup.

The negative (positive) coefficients on Before $_{i, t}\left(\right.$ After $\left._{i, t}\right)$ in Panel B affirm the results from Panel A that target firms engage less (more) in selling patents in the period prior to (after) the arrival of activists. Consistent with Akcigit et al. (2013), the positive estimate on Distance $_{j, i, t}$ indicates that firms are more likely to sell a patent that is distant from the firm's portfolio. Importantly, this effect is weaker for target 
firms pre-intervention when the coefficient on Distance $_{j, i, t} \times$ Before $_{i, t}$ is negative and significant in three out of four specifications. However, the propensity to sell distant patents is markedly stronger for target firms post-intervention when the coefficient on Distance $_{j, i, t} \times$ After $_{i, t}$ is positive and significant at $5 \%$ or $10 \%$ levels in all specifications.

In sum, targets of hedge fund activists are associated with a heightened propensity to sell patents peripheral to the firms' core expertise, adding to the consistent evidence that hedge fund interventions serve to refocus the scope of innovation. In addition, while we do not find that the rate of patent purchases by target firms differs from their matched firms (columns (3) and (4) of Panel A, Table 5), we report in the online appendix that purchases by target firms tend to take place with patents whose distance from the patent portfolio is smaller than that of purchases made by matched firms. That is, the refocusing takes place both with patent sales and purchases. We next ask whether the sale of patents also represents efficient reallocation of innovation resources to the buyers, in addition to the sellers.

We construct a patent-year $(j, t)$ level sample by merging the patent transaction database with the NBER patent database for citation information. The sample includes all the patents retained and sold by both targets and their matched firms, which allows us to estimate the dynamics of citations around patent transactions and to compare the difference between targets and non-targets. The regression specification is as follows:

$$
\text { Citation }_{j, t}=\sum_{k=-3}^{+3} \beta_{k} d[t+k]_{j, t}+\gamma \cdot \text { Control }_{j, t}+\alpha_{j}+\alpha_{t}+\varepsilon_{i, t}
$$

The dependent variable is the number of new citations an existing patent $j$ receives in year $t$. The key independent variables, $d[t+k]_{j, t}, k=-3, \ldots,+3$, are dummy variables for observations that are $k$ years from the event year, where an event is the sale of a patent by either a target firm within two years after intervention or a non-target firm within two years after the pseudo-event year. The control variable is log patent age. The regression incorporates year and patent (or technology class) fixed effects to absorb time- and patent-specific unobservable characteristics, and we cluster standard errors at the patent level. The regression results are reported in Table 6. 
[Insert Table 6 here.]

The coefficients on $d[t+k]_{j, t}, k=-3, \ldots,+3$ for target firms in column (1) exhibit a "V" shape pattern centered on the year of sale. In the three years before the sale the impact of the patents eventually sold post hedge fund activism is statistically equivalent to their own long run average, but in the subsequent three years there is a significant deterioration as evidenced by the significant $F$-statistics testing the difference, $d[t]-d[t-3]$. These patents are sold at the trough in terms of annual citations, but then regain the pace of diffusion afterwards under the new owner. In fact, the significant $F$-statistics on the difference suggest annual citations to target firms' patents that are sold are higher than the levels in the year of sale.

The evidence presented above is consistent with the idea that target firm patents were reallocated efficiently subsequent to the arrival of hedge fund activists. Of course, this reallocation ought to be assessed against a benchmark providing the dynamics in citations under a plausible counterfactual scenario. The first counterfactual that we consider is the sale of patents by the propensity-score-matched firms. Conditional on the patent sale, we ask whether the presence of the activist investor is associated with an abnormal pattern in citations indicated by whether the citations of patents sold by target firms differ from the citations of patents sold by the matched firms. Column (2) of Table 6 provides the regression results following patent sales at non-target matched firms. Citations to patents that will be sold see a small and insignificant decline prior to the sale, $d[t]-d[t-3]$. Post sale, the number of citations for these patents remains essentially flat. Importantly, the difference-in-differences analysis for the post-sale performance shows that the gain is significantly higher for target firms than non-target firms.

A plot of the coefficients $d[t+k]_{j, t}, k=-3, \ldots,+3$ for both groups of firms in Figure 2 provides the dynamics of citation counts. While the sale of patents by matched firms is preceded by a decline in citation count, the improvement is evident only for the targets of hedge fund activists. The joint pattern echoes the finding in Brav, Jiang, and Kim (2015b), who find that physical asset (plant) sales post hedge fund intervention exhibit better ex-post performance than plant sales under other circumstances. This evidence is consistent with the idea that activism triggers the reallocation of assets and "improved 
matching" of assets to new owners. A further breakdown of sold patents into patents that are "distant" and "close" to the firm's core portfolio (not tabulated) shows that the post-intervention improvement is about the same magnitude for both groups; however, the pre-intervention deterioration is unique to the “distant" group.

\section{[Insert Figure 2 here.]}

Though informative, Figure 2 does not address the potential endogeneity that hedge funds might have chosen to push for the sale of patents with the highest potential impact for a "short-term gain," a recurring criticism of activists. If the selection is based on unobserved characteristics not captured by the propensity score matching, the dynamics of citations in Figure 2 could be due to selection and are not conclusive evidence of an efficient patent relocation. In the absence of a random shock triggering patent sales, we instead reformulate the counterfactual to incorporate the possibility that patents sold postintervention were inherently better along unobservable dimensions. To be on the conservative side, we construct two counterfactuals for patents sold post-intervention: (1) the best (top quintile) patents retained by the matched firms in terms of increases in citations over the following three years and (2) the best (top quintile) patents held by the buyers. The last two columns of Table 6 explore the citation dynamics of patents sold post-activism against these two counterfactuals.

The evidence indicates that annual citations see a small and marginally significant decline up to the pseudo-event year in which target firms' patents were sold but then rebound significantly higher in the following three years. Importantly, the difference-in-differences analysis comparing the post-sale performance of patents sold by target firms to that of the best patents held by either the matched firms or the buyers indicates a significant incremental improvement (at the 5\% and 10\% levels). In other words, even if we take the premise by the critics of hedge fund activism that target firms sell their best patents for a short-term gain under the pressure from the activists and we assume that the activists are able to identify patents with the highest citation growth potential with high accuracy, the increases in citations over the following three years still seems to rise above the counterfactuals constructed to reflect such high hurdles. Moreover, the results in Column (4) also provide further evidence on the efficiency of the patent 
reallocation decision from the patent buyer's perspective. The results in Table 6 thus support the view that patent sales by firms targeted by hedge fund activists reflect an efficient reallocation for both the sellers and the buyers. ${ }^{18}$

\subsection{Redeployment of human capital}

The dynamics of patent transactions following hedge fund intervention suggest that a similar pattern could also exist in human capital redeployment. After all, a large portion of R\&D expenditures goes into hiring and incentivizing innovators, and early research has demonstrated that innovative human capital is an important determinant of firm performance (Seru (2014), Bernstein (2015)).

Following Bernstein (2015), we use the HBS patent and inventor database to classify three groups of inventors: a "leaver" is an inventor who leaves her firm during a given year, a "new hire" is an inventor who is newly hired by a given firm in a given year, and a "stayer" is an inventor who stays with her firm during a given year. For all three groups, we necessarily require that the inventor generate at least one patent prior to the year of intervention and generate at least one patent after the year of intervention. ${ }^{19}$

A two-step analysis sheds light on how hedge fund activism is associated with human capital redeployment. In the first step, we test whether hedge fund activism is associated with higher inventor mobility using the same difference-in-difference framework as equation (1) except that we replace the dependent variable with the logarithm of the number of leavers or new hires (plus one). The results are reported in Table 7 Panel A. The insignificant coefficients on I(Target) indicate that the unconditional rate of innovator departures and arrivals at target firms is similar to that of the matched peers. Nevertheless, within the five-year period subsequent to the arrival of activist hedge funds, the rate of innovator departures (arrivals) increases significantly (at the $10 \%$ and $1 \%$ levels) relative to the control firms by $6.2 \%(8.6 \%)$ in the specification with firm fixed effects.

\footnotetext{
${ }^{18}$ Building on earlier evidence that hedge funds facilitate asset reallocation in the form of sale of assets, segments, or even the whole firm (Greenwood and Schor (2009); Brav, Jiang, and Kim (2015b)), we show in the online appendix that asset divestures triggered by hedge fund activism are indeed accompanied by a $10-18 \%$ increase in departing inventors and 24-29\% increase in patent sales (all effects are significant at the 5\% level).

${ }^{19}$ Bernstein (2015) points to a limitation of the HBS patent and inventor database in that the relocation of an inventor is not recorded unless the transitioning inventor files patents in a new location. As a result, we are effectively constraining the sample to "frequent" patent filers, that is, we require at least one patent filing both before and after the intervention or relocation.
} 


\section{[Insert Table 7 here.]}

Next, we trace the productivity gains for all three groups of inventors post intervention. The sample now consists of inventor-firm-year $(l, i, t)$ observations. The regression specification is the same as in equation (1) except that the dependent variable is now the change between two three-year periods in the number of new patents (the first three columns of Table 7 Panel B) or new citations per patent (the last three columns). The first-difference specification automatically subsumes an innovator fixed effect. The sample includes all inventors who appear during three years before the event and in the event year who can be categorized as "stayers", "leavers", and "new hires," and essentially pools two cross sections. Inventors who cannot be categorized into the three categories are excluded from the sample. In the first cross section, the difference is taken between $[\mathrm{t}-3, \mathrm{t}-1]$ and $[\mathrm{t}-6, \mathrm{t}-4]$, where $t$ is the event (or pseudo-event) year. In the second cross section (defined as post-event, or $I($ Post $)=1$ ), the difference is taken between [t, $\mathrm{t}+2]$ and $[\mathrm{t}-3, \mathrm{t}-1]$. The three columns of the table cover the three groups of inventors. All regressions include year fixed effects.

Columns (1) and (4) show that "stayers" experience significantly higher improvement in productivity — both in terms of the quantity and quality of patents they file (1.088 more new patents and 1.958 more citations per patent) post hedge fund intervention—compared to "stayers" at matched firms during the same period. Such a phenomenon is consistent with a selection effect that the less productive inventors leave the firms, raising the average of the remainder or a treatment effect in which, the stayers have access to more resources and/or managerial support after the reduction. Both effects reflect favorably on the retention of innovators post hedge fund intervention.

Similar to the ex post performance of sold patents, the "leavers" also fare better at their new employers, although these effects are significantly weaker. The increase in their new patents is positive but marginally significant (column (2)), and the increase in the impact of their new patents is only marginally significantly higher than their peers (column (5)). More specifically, inventors who have departed shortly after hedge fund intervention later produce patents that receive about three citations per 
patent more than inventors in the control sample, suggesting that these individuals were able to land on "greener pastures."

These results, although striking, do not allow us to refute that a similar improvement would have occurred had the "leavers" remained as "stayers." However, if the alternative hypothesis were to hold, then the coefficient on $I\left(\right.$ Target $\left._{i}\right) \times I\left(\right.$ Post $\left._{i, t}\right)$ would be under-estimated for "stayers" because the departure induces an unusual negative survivorship bias (i.e., the better inventors leave). Thus, the performance improvement of at least one of the "stayers" or "leavers" cannot be attributed to selection. Finally, columns (3) and (6) show that "new hires" perform at or above par: They generate an abnormal number of new patents relative to new hires at non-target firms, but there is no significant improvement in the quality of these new patents.

\section{Causality}

Thus far we have shown that hedge fund activism is associated with an overall reorganization in which target firms reallocate underutilized assets, and these innovative resources (patents and inventors) match to better-suited owners and employers. The consistency of results from different viewpoints makes it unlikely that the findings should be attributed to alternative economic channels, some of which have already been assessed in the earlier sections, such as the selective turnover of patents and innovators. Moreover, it is difficult to justify the launching of an activism campaign if the same outcome would have taken place had the activist merely picked the stock of the target firm and remained as a passive investor. Activists tend to hold a concentrated equity stake in the target firm until the resolution of their goals, a holding period that averages close to two years (see Brav et al. (2008)). It is hard to argue that they would willingly hold undiversified positions and be subject to costly engagements (Gantchev (2013)) if these were not necessary means to achieve their goals. It is also important to point out that we purposely do not focus on the effect of hedge fund activism on a randomly chosen target firm since selective targeting is central to the success of the investment strategy. The more relevant treatment effect is thus whether the same changes we have documented would have taken place had the hedge funds remained passive owners in the same targets. We conduct four tests to separate treatment (intervention) from mere stock picking. 


\subsection{Mean reversion and voluntary changes}

One competing view holds that activists are informed and sophisticated investors and are therefore able to target firms whose general business strategies—which include innovative strategies—were about to go through voluntary changes in the same direction. ${ }^{20}$ After all, it is well known that target firms experience a deterioration in performance prior to hedge fund intervention. The subsequent recovery, including changes to innovation, reflects a reversion to a long-run mean that is simply anticipated by the activist.

Our propensity score matching is structured to address one element in the mean reversion alternative by controlling for firm performance in event years $t-1$ and $t-3$, along with other attributes such as industry, firm size, and market-to-book ratio. The propensity-score-matching suggests the quantity and quality of innovation do not rebound in the years that correspond to the post-intervention period captured by the sign of $I($ Post $)$ in Table 3. Mean reversion in innovative performance does not take place. Any traces of mean reversion should manifest in a positive slope on $I($ Post $)$. Instead, it is either negative and marginally significant when we examine the number of new patents in column (3), or insignificant in column (4) when we examine citations per patent.

Of course, activist hedge funds select which firms to target based on both observable and unobservable attributes, and it is still possible that our propensity score matching omits some unobservable factors that drive subsequent changes in innovation. To this end, we consider the subsample of openly confrontational events in which management resisted the hedge fund's agenda. If we were to observe a positive treatment effect for this subsample it would be more challenging to attribute the changes to the incumbent management's voluntary and planned actions. We define hostile events as those in which the activist's tactics involve either actual or threatened proxy contests and lawsuits or shareholder campaigns of a confrontational nature. These include public denouncements of management

\footnotetext{
${ }^{20}$ Consider the recent Trian vs. DuPont case described in footnote 5. Trian Partners spent roughly $\$ 8$ million to launch a proxy battle against DuPont in May 2015, more than two years after the initial investment in the target company. The alternative hypothesis is that the changes, which include director turnover, a $\$ 5$ billion share buyback, a major cost-cutting initiative, and a spinoff (Chemours), would have happened absent the activist's advocacy and insistence.
} 
or shareholder proposals aimed at the ouster of the CEO. Hostile events account for $23 \%$ of our sample, similar to the fraction that hostile events comprise relative to the entire sample of activism events (21\%). The results are reported in Table 8. As with the results for the broader sample reported in Table 3, openly confrontational events experience a decline in $R \& D$ expenditures (significant at the $10 \%$ ) although the slope on $\mathrm{R} \& \mathrm{D} /$ assets is insignificant. Importantly, we see that target firms file for $14.8 \%$ more patent applications compared to the matched firms, controlling for both firm and year fixed effects (significant at the $10 \%$ ), while patents filed post intervention by this subsample receive $13.5 \%$ more citations (significant at the 10\%) than patents filed by matched firms during the same period. The fact that events in which management tended to oppose the activist agenda see an effect of the same magnitude as the overall sample is consistent with the view that activists' agendas tend to influence, at least partially, their target firms' innovation.

\section{[Insert Table 8 here.]}

\section{$5.213 G$ to $13 D$ switches: Stock picking vs. intervention}

Our second test is designed to differentiate between activists' stock picking ability, the skill to anticipate improving fundamentals at the target firm absent the activists' effort, from post-event changes that are likely caused by the intervention. The legal framework for block ownership disclosure offers an ideal setting to separate the two. Investors holding beneficial ownership of more than $5 \%$ but below $20 \%$ for purely an "investment purpose" with no intent to influence control or policies are usually eligible to file a less stringent schedule $13 \mathrm{G}$ with the SEC instead of a schedule 13D (under Exchange Act Section 13(g) and Regulation 13D-G). A schedule 13G (13D) filing can be equated to a passive (activist) position for identification purposes if the following two conditions hold: First, an investor who files a 13G cannot take actions that could be interpreted as influencing firm policies and control, including actively "communicating" with management regarding firm strategies; second, an investor with a passive stance would not want to file a schedule 13D. The first condition is essentially the current law while the second condition is incentive compatible. Since schedule 13D filings entail added legal obligations, including a 
much shorter period before disclosure is due and further details required in disclosure, a true passive investor should not find it appealing to file a Schedule 13D. ${ }^{21}$

A small sample of "13G-to-13D" switches allows us to filter out the treatment effect by focusing on changes in firm performance subsequent to the switch versus that of firms held by hedge funds who keep the $13 \mathrm{G}$ status. A switch is required by law if a formerly passive investor decides that it may now want to take actions to influence control. Importantly, a switch usually does not come with significant ownership changes - the only major change is that the investor stance changes from passive to active. As a result, the switch provides an unusual setting in which the ownership (and hence stock picking) does not interfere with intervention. Moreover, our identification comes narrowly from the same hedge fund-firm paring, and therefore unobserved fund or firm heterogeneities can also be filtered out with fixed effects.

We begin with the sample of all firms in which we observe a $13 \mathrm{G}$ filing by one of the hedge fund activists that had intervened in one of the 553 innovative targets. We then identify the subsample of $13 \mathrm{G}$ filings in which we can find a subsequent switch to a 13D filing (the switch sample). As with our previous setup, we keep only those firms that file for a patent at least once prior to the filing of a Schedule $13 \mathrm{G}$ and retain observations from five years prior to and five years post filing. There are 79 interventions in our sample in which activism was initiated by the activists' switch from a schedule 13G to a 13D filing. We then estimate the following specification:

$$
y_{i, t}=\alpha_{t}+\alpha_{i}+\alpha_{f}+\beta_{1} \cdot I(\text { Post }) \times I(13 G \text { to } 13 D)+\beta_{2} \cdot I(\text { Post })+\gamma \cdot \text { Control }_{i, t}+\varepsilon_{i, t}
$$

The dependent variable, $y_{i, t}$, is $\mathrm{R} \& \mathrm{D}$ expenditures scaled by firm assets, the natural logarithm of one plus patent counts, or the natural logarithm of one plus lifetime citations per patent. I(Post) is a dummy variable equal to one if the firm-year observation is within $[t+1, t+5]$ years after the year of the schedule $13 \mathrm{G}$ filing for events in which there is no subsequent switch and the year of the switch to a schedule 13D for the subsample of switches. $I(13 G$ to $13 D)$ is a dummy variable equal to one if the event is a switch from a schedule $13 \mathrm{G}$ to $13 \mathrm{D}$ and zero otherwise. Control $_{i, t}$ is a vector of control variables including market

\footnotetext{
${ }^{21}$ For example, Schedule 13D requires instant filing of an amendment if there is any "material" change in the activist's action, including ownership changes of $1 \%$ or more in either direction. Schedule 13G, instead, requires disclosure of less information, and allows for a longer delay in ownership disclosure, i.e., within 45 days after the end of the calendar year.
} 
capitalization and firm age (both in logarithmic terms), and $\alpha_{t}, \alpha_{i}$ and $\alpha_{f}$ represent year, firm, and hedge fund fixed effects, respectively.

The regression results, reported in Table 9, indicate that relative to the firms in which the activist hedge fund chose not to switch from a passive to an activist approach, target firms with a switch to a schedule 13D file about $11.1 \%$ more patent applications (significant at the 10\%), and their patents filed collect $16.3 \%$ more citations (significant at the 10\%), controlling for firm size and age and year and firm fixed effects. As with the main sample, we do not find that a switch leads to a change in $R \& D$ expenditures scaled by firm assets. Overall, innovation as proxied by the number of new patents and their citations expands after a passive hedge fund blockholder takes an activist approach. Given that only the activist's stance, and not its ownership, changes at the switching point, the test provides a cleaner identification of the impact of activist intervention beyond mere stock picking.

\subsection{Market response to patent grant announcements}

The third test is designed to identify a causal impact of hedge fund activism by exploiting the long and random delay between the patents' application and grant dates. We first limit the sample of patents to those that were applied for by target firms prior to the arrival of the activist (or pseudo-event time for the controls). Table 10 Panel A shows that the median time interval is about two and half years (average time interval is about three years). The variance at about one and half years is also sizable. Both the delay and variance are indistinguishable between targets and non-targets. One can also plausibly argue that the exact timing of a patent grant is not under the control of either the filer or the activist, nor should the activist possess superior information to predict the exact date. ${ }^{22}$

[Insert Table 10 here.]

As such, patents that were filed during the four-year period prior to intervention (i.e., [t-48, t-1] months) and granted during the 12-month period around the intervention month (i.e., $[\mathrm{t}-6, \mathrm{t}+6]$ months) were likely produced under very similar circumstances. However, if hedge fund activism has an impact on innovation, then the market should perceive that patents granted during $[t+1, t+6]$ would be put into

${ }^{22}$ See Lerner and Seru (2015) for a detailed discussion on the patenting process at the USPTO. 
more productive use than those granted during $[\mathrm{t}-6, \mathrm{t}-1]$. Hence, a more positive stock market response to patents granted post-activism is indicative of a market belief that the patents produced during the same "old" regime are worth more under the "new" regime. Table 10 Panel B provides supportive evidence.

The dependent variable in all four regressions is the abnormal stock return over the five-day window centered around the patent granting date, where the abnormal return is defined as the buy-and-hold stock return of the firm in excess of the CRSP value-weighted market return. The sample in column (1) includes all patents granted during the $[\mathrm{t}-6, \mathrm{t}+6]$ (month) window around hedge fund activism and the sample in column (2) shrinks the window to $[t-3, t+3]$. All regressions incorporate firm fixed effects, and the monthly fixed effects for the length of time between the patent application and grant dates. It is plausible that patent applications incurring a longer waiting time are disproportionately represented in the $[\mathrm{t}+1, \mathrm{t}+6]$ (or $[\mathrm{t}+1, \mathrm{t}+3])$ group (i.e., $I($ Post $)=1$ ), and that the duration could be correlated with patent quality notwithstanding the randomness in the exact timing of approval. Hence, the application-approval time lag fixed effects (at the monthly level) subsume all the unobserved heterogeneity correlated with the time to approval. The estimated coefficients on the key independent variable, $I($ Target $) \times I($ Post $)$, range from 31 to 33 basis points (significant at the 5\% and 10\% levels), suggesting that the market value of patents granted goes up significantly post intervention, even though the patents were produced and filed before the arrival of the activists. The last two columns of Table 10 Panel B apply the same regression to the smaller subset of activism events that are 13G-to-13D switches. Again, the market reaction to patent grants during the post-switch period is about 36 to 45 basis points higher, though with lower significance due to the much smaller subsample of events. ${ }^{23}$ Therefore, this test further isolates the effects of hedge fund stock picking and that of intervention.

One can also argue that hedge funds might selectively target firms with high-impact patents in the pipeline for formal approval based on public or private information about patent quality. Note that pending patent applications is public information, hence the additional information about pending patent quality revealed by the hedge fund action should be impounded in the stock price during the activism

\footnotetext{
${ }^{23}$ Results are robust if we tighten up the sample to patents filed during [t-36, $\left.t-24\right]$ months so that their expected grant dates are around the intervention date.
} 
announcement window. The incremental return upon patent approval reflects the additional value of the patent under improved management, adjusted by the resolution of the remaining uncertainty in the granting of the patent as well as its timing.

\section{Conclusion}

This paper studies how and to what extent hedge fund activism impacts corporate innovation. Although target firms' R\&D expenditures drop in the five years following hedge fund intervention, patent quantity and quality actually improve, suggesting that target firms' innovation becomes more efficient. We identify three plausible mechanisms through which hedge fund activists improve target firms' innovation efficiency. First, target firms refocus their effort to their core innovation expertise and explore updated technologies in these areas. Second, hedge fund activists are able to better reallocate innovative resources. Patents sold by target firms within two years post hedge fund intervention receive significantly more citations relative to their matched peers, reversing a pattern of declining citations prior to the intervention. Third, the structural changes associated with the entry of activists leads to the redeployment of human capital crucial to the innovation process. Inventors retained by target firms are more productive than those at non-target firms, and inventors who leave following hedge fund intervention become more productive with their new employers. Finally, we show that the link between hedge fund interventions and improvements in innovation efficiency seems at least partially driven by the effort of the activists rather than their selection abilities. 
Appendix A-1. Variable Definition and Description

\begin{tabular}{|c|c|}
\hline Variable & Definition and Description \\
\hline \multicolumn{2}{|r|}{ a. Innovation Variables } \\
\hline R\&D Expense & Research and development expenses (XRD). \\
\hline R\&D Ratio & Research and development expenses (XRD) scaled by total assets (AT). \\
\hline New Patents & Number of patent applications filed by a firm in a given year. \\
\hline Average Citations & $\begin{array}{l}\text { Average number of lifetime citations received by the patents applied for by a firm } \\
\text { in a given year. }\end{array}$ \\
\hline Originality & $\begin{array}{l}\text { One minus the Herfindahl index of the number of cited patents across 2-digit } \\
\text { technological classes defined by the NBER patent database. }\end{array}$ \\
\hline Generality & $\begin{array}{l}\text { One minus the Herfindahl index of the number of patents across 2-digit } \\
\text { technological classes which cite the specific patents. }\end{array}$ \\
\hline Explorative & $\begin{array}{l}\text { Percentage of explorative patents filed in a given year by the firm; a patent is } \\
\text { explorative if at least } 80 \% \text { of its citations do not refer to existing knowledge, which } \\
\text { includes all the patents that the firm invented and all the patents that were cited by } \\
\text { the firm's patents filed over the past five years. }\end{array}$ \\
\hline Exploitative & $\begin{array}{l}\text { Percentage of exploitative patents filed in a given year by the firm; a patent is } \\
\text { exploitative if at least } 80 \% \text { of its citations refer to existing knowledge, which } \\
\text { includes all the patents that the firm invented and all the patents that were cited by } \\
\text { the firm's patents filed over the past five years. }\end{array}$ \\
\hline Diversity & $\begin{array}{l}\text { One minus the Herfindahl index of the number of patents filed by a firm in the past } \\
\text { across 2-digit technological classes defined by the NBER patent database. }\end{array}$ \\
\hline Distance (Patent to Firm) & $\begin{array}{l}\text { See Appendix A-2. Please refer to Akcigit, Celik and Greenwood (2015) for a } \\
\text { detailed discussion of this measure. }\end{array}$ \\
\hline \multicolumn{2}{|r|}{ b. Innovative Resource Reallocation } \\
\hline Inventor leavers & $\begin{array}{l}\text { An inventor is a leaver of firm } i \text { in year } t \text { if she generates at least one patent in firm } i \\
\text { between }[t-3, t-1] \text { and generate at least one patent in a different firm between } \\
{[t+1, t+3] \text {; identified from Harvard Business School patenting database. }}\end{array}$ \\
\hline Inventor new hires & $\begin{array}{l}\text { An inventor is a new hire of firm } i \text { in year } t \text { if she generates at least one patent in } \\
\text { another firm between }[t-3, t-l] \text { and generate at least one patent in firm } i \text { between } \\
{[t+1, t+3] \text {; identified from Harvard Business School patenting database. }}\end{array}$ \\
\hline Patent Sell & $\begin{array}{l}\text { Number of patent sold by a firm. Identified from Google Patent Transactions } \\
\text { Database compiled by USPTO. }\end{array}$ \\
\hline Patent Buy & $\begin{array}{l}\text { Number of patent bought by a firm. Identified from Google Patent Transactions } \\
\text { Database compiled by USPTO. }\end{array}$ \\
\hline \multicolumn{2}{|r|}{ c. Firm Characteristics } \\
\hline Age & Number of years since IPO, as reported in Compustat. \\
\hline Total Assets & Total assets (AT). \\
\hline MV & $\begin{array}{l}\text { Market value of the firm is defined as common shares outstanding (CSHO) times } \\
\text { the share price. }\end{array}$ \\
\hline ROA & $\begin{array}{l}\text { Earnings before interest, taxes, depreciation, and amortization (OIBDP) scaled by } \\
\text { lagged total assets (AT). }\end{array}$ \\
\hline $\mathrm{M} / \mathrm{B}$ & $\begin{array}{l}\text { The market value of the firm, defined as the sum of the market value of common } \\
\text { equity, the debt in current liabilities (DLC), long-term debt (DLTT), preferred stock } \\
\text { liquidating value (PSTKL) and deferred taxes and investment tax (TXDITC), } \\
\text { scaled by the book value of the firm (AT) }\end{array}$ \\
\hline Leverage & $\begin{array}{l}\text { Book debt value (sum of debt in current liabilities (DLC) and long-term debt } \\
\text { (DLTT)) scaled by total assets (AT). }\end{array}$ \\
\hline
\end{tabular}




\section{Appendix A-2. Distance between a Patent and a Firm's Technology Stock}

Following Akcigit, Celik and Greenwood (2015), the distance between a technology class X and Y is constructed as

$$
d(X, Y) \equiv 1-\frac{\#(X \cap Y)}{\#(X \cup Y)}
$$

where $\#(X \cap Y)$ denotes the number of all patents that cite at least one patent from technology class $\mathrm{X}$ and at least one patent from technology class $\mathrm{Y} ; \#(X \cup Y)$ denotes the number of all patents that cite at least one patent from technology class $\mathrm{X}$ or at least one patent from technology class $\mathrm{Y}$, or both. The distance of a patent $p$ to a firm $f$ 's technology stock is computed by calculating the average distance of $p$ to each of the patents owned by $f$. Specifically,

$$
d_{\imath}(p, f)=\left[\frac{1}{\left\|P_{f}\right\|} \sum_{p^{\prime} \in P_{f}} d\left(X_{p}, Y_{p^{\prime}}\right)^{\iota}\right]^{1 / \iota}
$$

where $\boldsymbol{l}$ is the weighting parameter and $0<\boldsymbol{\imath} \leq 1 . P_{f}$ denotes the set of all patents that were ever invented by firm $f$ prior to patent $p$, and $\left\|P_{f}\right\|$ denotes its cardinality. In this paper, we follow Akcigit, Celik and Greenwood (2015) and use $\boldsymbol{\imath}=0.33,0.66$ for our analyses. 


\section{Appendix A-3. Identifying Patent Transactions}

This appendix provides a detailed description of the method used to identify patent transactions following the procedure in $\mathrm{Ma}$ (2015). We first introduce the raw dataset on patent assignments and then present the methodology used to identify patent transactions; specifically, patent assignments other than transfers from an inventor to the firm she works at or from a subsidiary to its corporate parent.

We begin with the raw patent assignment database, downloaded from the United States Patent and Trademark Office (USPTO) patent assignment files, hosted by Google Patents. A patent assignment is the transfer of (or part of) an owner's property right in a given patent or patents, and any applications for such patents. The patent transfer may occur on its own or as part of a larger asset sale or purchase. These files contain all records of assignments made to U.S. patents from the late 1970s. The original files are then parsed and combined to serve as the starting raw dataset, including all patents assigned from an inventor to the firm, from a firm to an inventor, from one inventor (firm) to another inventor (firm).

We make use of the following information for the purpose of identifying patent transactions. First, in regards to patent assignment information, we retrieve information on the assignment date, the participating parties, including the assignee (the "buyer") and the assignor (the "seller") in a transaction, and comments on the reason for the assignment. Some important reasons include assignment of assignor's interest, security agreement, merger, and change of names. Second, in regards to patent information, we retrieve information on patent application and grant dates, identification numbers (patent number and application number), and patent title. We then merge the raw assignment data with the USPTO patent databases so as to gather additional information on the original assignee and patent technology classes. We also combine the dataset with the inventor level data maintained at Harvard Business School (HBS), which allows us to identify the inventor(s) of any given patent. Since we focus on utility patents, we remove entries regarding design patents.

Next, we standardize the names of the assignee and assignor in the raw patent assignment dataset, patent original assignee names reported in the USPTO databases, and inventor names in HBS inventor database. Specifically, we employ the name standardization algorithm developed by the NBER Patent Data Project. This algorithm standardizes common company prefixes and suffixes, strips names of punctuation and capitalization and it also isolates a company's stem name (the main body of the company name), excluding these prefixes and suffixes. We keep only assignment records of which the assignment brief is included under "assignment of assignor's interest" or "merger." That is, we remove cases when the reason for the assignment is clearly not transactions such as a "change of names."

The central part of the identification of a patent transaction uses several basic principles that predict how patent transactions appear in the data. First, the initial assignment in a patent's history is less likely to be a patent transaction. It is more likely to be an original assignment to the inventing firm. Note that this 
principle is more helpful on patents granted after 1980, when the raw dataset started to be systematically updated. Second, if an assignment record regards only one patent with the brief reason being "assignment of assignor's interest," it is less likely to be a transaction, as it should be rare that two parties transact only one patent in a deal (see Serrano (2010)). Third, if the assignor of an assignment is the inventor of the patent, it is less likely that this assignment is a transaction, but instead more likely to be an employee inventor who assigns the patent to her employer. Fourth, if both the assignor and assignee are corporations, it is likely that this assignment is a transaction, with the exception that the patent is transferred within a large corporation (from a subsidiary to the parent, or between subsidiaries). Based on these principles, the algorithm below is a process in which we remove cases that are unlikely to be patent transactions. The steps we take are:

1. Check if the assignment record date coincides with the original grant date of the patent (the date when the patent was first issued). If it does we label the assignment as a "non-transaction" and it is removed from the data set, otherwise we move to Step 2.

2. Check whether the patent assignment record contains only one patent and is the first record for this patent, with "assignment of assignor's interest" as the assignment reason. If the answer is in the affirmative we move to Step 3, otherwise the record is labeled as a "potential transaction" and we move to Step 4.

3. Compare the assignee in the assignment record with the assignee as of the original patent assignment in the USPTO. Similarly, compare the assignor in the assignment record with the inventor names in HBS patent database. If the assignee name coincides, or the assignor is the patent inventor(s) plus the assignee is a firm, we then categorize the assignment as a "non-transaction", and it is removed from the dataset. This constraint covers cases in which either the assignee or assignor have slightly different names across different databases, otherwise the record is labeled as a "potential transaction" and we move to Step 4.

4. Perform the analysis described in Step 3 on the "potential transaction" with one minor change: When comparing the assignee in the assignment record with the assignee as of the original patent assignment in USPTO, and when comparing the assignor in the assignment record with the inventor names in HBS patent database, we allow for spelling errors captured by Levenshtein edit distance less or equal to $10 \%$ of the average length of the two strings under comparison, and we denote this name as "roughly equal to." Then, if the assignee name roughly coincides, or the assignor is roughly the patent inventor(s) plus the assignee is a firm, then the assignment is categorized as a "nontransaction" and is removed from the data set, otherwise the record is kept as a potential "transaction" and we move to Step 5. 
5. Compare the standardized names and stem names of the assignee and assignor of records in the "potential transactions." If the names coincide, this is consistent with an internal transfer and the record is labeled as a "non-transaction." If the names do not coincide the record is labeled as a "transaction." 


\section{Appendix A-4. Additional Considerations Involving the Patent Data}

This appendix is structured following the checklist approach advocated by Lerner and Seru (2015) (see their Table 10). Lerner and Seru (2015) suggest that researchers using patent data confirm that their analyses address the following questions.

1. To what extent are the key policy changes occurring around times when patenting and citations per patent accelerated?

This feature of the data has a limited influence on the analyses in our setting since the activism events are staggered over the sample period and time trends are controlled by both the propensity score matching algorithm and the year fixed effects. We also show in the online appendix that the results presented in Section 3 continue to hold when we repeat the analysis using activism events that occurred over the first part of our sample period, 1994-2002.

2. Are firms in industries that experienced a surge of patenting or in citations per patent (e.g., computers and electronics) included in one of the sub-populations being analyzed?

This concern is clearly important and that is why we implement the propensity matching within each industry. Our results are also robust when we study specific industries as reported in Section 3 and Table 3, Panel B.

3. To what extent are firms in states that experienced a surge of patenting or citations per patent (e.g., California and Massachusetts) included in one of the sub-populations being analyzed?

This concern does not apply to the analysis in this paper although, as pointed above, we control for industry affiliation directly in our propensity score matching.

4. Are firms with features akin to those that experienced a surge in patenting or citations per patent (e.g., those with a high market-to-book value) included in one of the sub-populations being analyzed?

Controlling for firm characteristics that are correlated with patenting activities is an important factor that we take into consideration by implementing the propensity score matching using firm size (logarithm of assets), market-to-book ratio, and return on assets (ROA) measured at t-1, as well as the change in the target firm ROA measured between years $t-3$ and $t-1$ so as to capture pre-event trends of deterioration in the operating performance of target firms. As we report in the text, our results are both qualitatively and quantitatively similar when we add more firm characteristics to the calculation of propensity scores.

5. To what extent are the patterns seen consistent across the sample (e.g., across the entire period under study), or do they vary with in ways that might be associated with unobserved factors that may be 
driving patenting practice? Are the coefficients of the effect consistent across the sample, or being driven by a sub-group?

As we report in the text, our results are robust to different time periods and different industries categorized by their innovation input-output lag. The online appendix provides two additional robustness checks. First, we restrict the definition of "innovative" target firms to those that have at least five patents prior to the year of the intervention and find qualitatively similar evidence. Second, we adopt a negative binomial specification instead of that in equation (1), including year and firm fixed effects, and find similar results.

6. May the results be driven by selection biases, due to the researchers' inability to observe pending patents or not-yet cited patents? Are the results robust to treat these truncation biases in different ways?

This is an important issue to consider. We correct for truncation using the correcting factor proposed in Hall, Jaffe, and Trajtenberg (2001). We also confirm that the results are robust in the first subsample, 1994-2002, which is less likely to be influenced by this truncation problem.

7. Could the results be driven by the exit of firms, and the likelihood that some or all of the patents pending at the time of exit will not be assigned to this firm, but rather to a successor entity? To what extent may this exit truncation problem be linked to the phenomenon under study?

We compare the exit behavior of the real target firms and the propensity score matched firms in Table A1 of the online appendix and observe no difference in the target and matched control firm exit behavior.

8. Is there any way to ascertain the extent to which the firms under study may be engaging in misleading assignment practices, in order to disguise their technological strategy from competitors?

As we report in the text, target firms are matched to controls based on several pre-event firm characteristics that drive targeting. There is no reason to expect that deceptive patent assignment practices would differ systematically across target and control firms.

9. To what extent may the limitations of the concordances between patent assignees and firms be systematically affecting the results of the analysis (a consideration particularly relevant when the implications of the market for corporate control on innovation are being studied)?

We adopt the dynamic concordance between USPTO assignees and public firms, which controls for this constraint to some extent. This issue is particularly important in analysis regarding patent transactions (re-assignments) as discussed in Appendix A-3. In that analysis we make sure the reassignments are not capturing the reallocation of IP within a firm (between different divisions) by directly analyzing their division names. 
10. Do the citation practices of the firms under study differ significantly from the norm, which might suggest that firms are engaging in strategic use of citations?

This concern is particularly important when patent citation records are used as a proxy of information and knowledge flows from one innovator to another. This paper does not utilize patent data in this manner. One related implication of this concern is that firms might strategically cite their own patents, and we attempt to mitigate this concern by removing all self-citations made by target and control firms. 


\section{References}

Acharya, Viral, and Krishnamurthy Subramanian, 2009, Bankruptcy codes and innovation, Review of Financial Studies 22, 4949-4988.

Aghion, Philippe, John Van Reenen, and Luigi Zingales, 2013, Innovation and institutional ownership, American Economic Review 103, 277-304.

Akcigit, Ufuk, Murat Alp Celik, and Jeremy Greenwood, 2015, Buy, keep or sell: Economic growth and the market for ideas, Econometrica, forthcoming.

Almeida, Heitor, Po-Hsuan Hsu, and Dongmei Li, 2013, Less is more: Financial constraints and innovative efficiency, Working paper, University of Illinois.

Aslan, Hadiye, and Praveen Kumar, 2016, The product market effects of hedge fund activism, Journal of Financial Economics, 119(1), pp.226-248.

Bebchuk, Lucian, Alon Brav, and Wei Jiang, 2015, The long-term effects of hedge fund activism, Columbia Law Review, 115(5), 1085-1156.

Becht, Marco, Julian Franks, Colin Mayer, and Stefano Rossi, 2009, Returns to shareholder activism: Evidence from a clinical study of the Hermes UK Focus Fund, Review of Financial Studies 22, 30933129.

Becht, Marco, Julian Franks, Jeremy Grant and Hannes Wagner, 2015, The Returns to Hedge fund Activism: An International Study, Working paper No. 402/2014, ECGI Finance.

Bena, Jan, and Kai Li, 2014, Corporate innovations and mergers and acquisitions, Journal of Finance 69, 1923-1960.

Bernstein, Shai, 2015, Does going public affect innovation? Journal of Finance 70(4), 1365-1403.

Bessen, James E., Michael J. Meurer, and Jennifer Laurissa Ford, 2011, The private and social costs of patent trolls, Regulation 34(4), pp. 26-35.

Brav, Alon, Wei Jiang, Frank Partnoy, and Randall Thomas, 2008, Hedge fund activism, corporate governance, and firm performance, Journal of Finance 63, 1729-1775.

Brav, Alon, Wei Jiang, and Hyunseob Kim, 2015a, Recent advances in research on hedge fund activism: Value creation and identification, Annual Review of Financial Economics, forthcoming.

Brav, Alon, Wei Jiang, and Hyunseob Kim, 2015b, The real effects of hedge fund activism: Productivity, asset allocation, and labor outcomes, Review of Financial Studies, 28(10), 2015.

Chemmanur, Thomas, and Xuan Tian, 2013, Anti-takeover provisions, innovation, and firm value: A regression discontinuity analysis, Working paper, Indiana University.

Clifford, Christopher P., 2008, Value creation or destruction? Hedge funds as shareholder activists, Journal of Corporate Finance 14, 323-336.

Coffee Jr., John C., and Darius Palia, 2015, Wolf at the Door: The impact of hedge fund activism on Corporate Governance, forthcoming Journal of Corporation Law.

Custódio, Cláudia, Miguel A. Ferreira, and Pedro Matos, 2013, Do general managerial skills spur innovation? Working paper No. 376, ECGI Finance.

Dass, Nishant, Vikram Nanda, and Steven Chong Xiao, 2015, Truncation bias in patent data: Does it explain why stock-liquidity seemingly reduces innovation?, Working paper, Georgia Institute of Technology.

Gantchev, Nickolay, 2013, The costs of shareholder activism: Evidence from a sequential decision model, Journal of Financial Economics 107, 610-31. 
Gompers, Paul, 1996, Grandstanding in the Venture Capital Industry, Journal of Financial Economics 42(1), 133-156.

Greenwood, Robin and Michael Schor, 2009, Investor activism and takeovers, Journal of Financial Economics 92, 362-375.

Griliches, Zvi, Ariel Pakes, and Bronwyn H. Hall, 1988, The value of patents as indicators of inventive activity, Working paper No. 2083, National Bureau of Economic Research.

Hall, Bronwyn H., Adam B. Jaffe, and Manuel Trajtenberg, 2001, The NBER patent citation data file: Lessons, insights and methodological tools, Working paper No. 8498, National Bureau of Economic Research.

Hall, Bronwyn, Adam B. Jaffe, and Manuel Trajtenberg, 2005, Market value and patent citations, RAND Journal of Economics 36, 16-38.

Hall, Bronwyn H., Zvi Griliches, and Jerry A. Hausman, 1986. Patents and R\&D: Is there a lag? International Economic Review 27, 265-283.

He, Zhongzhi, Jiaping Qiu, and Tingfeng Tang, 2014, Hedge fund activism and corporate innovation, Working paper, McMaster University.

Holmstrom, Bengt, 1989, Agency costs and innovation, Journal of Economic Behavior and Organization $12,305-327$.

Jensen, Michael C., 1986, Agency costs of free cash flow, corporate finance, and takeovers, American Economic Review 76, 323-29.

Kerr, William R., and Ramana Nanda, 2015, Financing innovation, Annual Review of Financial Economics 7, 445-462.

Klein, April and Emanuel Zur, 2009, Entrepreneurial shareholder activism: Hedge funds and other private investors, Journal of Finance 64, 187-229.

Kogan, Leonid, Dimitris Papanikolaou, Amit Seru and Noah Stoffman, 2015, Technological innovation, resource allocation and growth, Quarterly Journal of Economics, forthcoming.

Krishnan C.N.V., Frank Partnoy, and Randall S. Thomas, 2015, Top Hedge Funds and Shareholder Activism, Working paper, Vanderbilt University.

Lai, Ronald, Alexander D’Amour, Amy Yu, Ye Sun, and Lee Fleming, 2013, Disambiguation and coauthorship networks of the U.S. patent inventor database (1975-2010), Harvard Business School.

Lerner, Josh, Morten Sorensen, and Per Stromberg, 2011, Private equity and long-run investment: The case of innovation, Journal of Finance 66, 445-477.

Lerner, Josh and Amit Seru, 2015, The use and misuse of patent data: Issues for corporate finance and beyond, Working paper, Harvard University and University of Chicago.

Ma, Song, 2015, The life cycle of corporate venture capital, Working paper, Duke University.

Manso, Gustavo, 2011, Motivating innovation, Journal of Finance, 66(5), 1823-1860.

Scharfstein, David, and Jeremy Stein, 2002, The dark side of internal capital markets: Divisional rentseeking and inefficient investment, Journal of Finance 55, 2537-2564.

Serrano, Carlos, 2010, The dynamics of the transfer and renewal of patents, RAND Journal of Economics 41, 686-708.

Seru, Amit, 2014, Firm boundaries matter: Evidence from conglomerates and R\&D activity, Journal of Financial Economics 111, 381-405. 
Shapiro, Carl, 2001, Navigating the patent thicket: Cross licenses, patent pools, and standard setting, in Innovation Policy and the Economy, Vol. 1, 119-150, ed. By Adam B. Jaffe, Josh Lerner, and Scott Stern, MIT Press.

Sorensen, J., and T. Stuart, 2000, Aging, obsolescence and organizational innovation, Administrative Science Quarterly 45, 81-112.

Stein, Jeremy, 1988, Takeover threats and managerial myopia, Journal of Political Economy 96, 61-80.

Stein, Jeremy, 1989, Efficient capital markets, inefficient firms: A model of myopic corporate behavior, Quarterly Journal of Economics 104, 655-669.

Stein, Jeremy, 2003, Agency, information and corporate investment, Handbook of the Economics of Finance 1, 111-165. 


\section{Figure 1. Innovation Around Hedge Fund Activism}

This figure presents the dynamics in innovation, as measured by the number of patent applications and their subsequent lifetime citations, in the years around the targeting by hedge fund activists. We employ the sample of hedge fund targets and propensity-score matched firms, retaining only those target firms that file for a patent at least once prior to the event with at least one positive $R \& D$ expenditure within the five-year window prior to the intervention. The unit of observation is at the firm $(i)$-year $(t)$ level. The coefficients and 95\% confidence intervals are estimated from the following specification:

$$
\text { Innovation }_{i, t}=\sum_{k=-3}^{+5} \lambda_{k} d[t+k]_{i, t}+\sum_{k=-3}^{+5} \beta_{k}\left\{d[t+k]_{i, t} \times I\left(\text { Target }_{i}\right)\right\}+\gamma \cdot \text { Control }_{i, t}+\alpha_{i}+\alpha_{t}+\varepsilon_{i, t},
$$

The dummy variable $d[t+k]$ is equal to one if the firm observation is $k$ years from the hedge fund activism event year (pseudo-event year for the control firms), and zero otherwise. We plot the $\beta_{k}$ coefficients, which are the estimates representing the differences in trends in innovation between hedge fund targets and the matched control firms. The dependent variable in Panel A is R\&D dollars scaled by total assets, that in Panel B is the logarithm of the number of patents filed by firm $i$ in year $t$, and that in Panel $\mathrm{C}$ is the logarithm of the average lifetime citations received by patents filed by the firm in year $t$. Control variables include the natural logarithm of firm market capitalization and firm age. All specifications include firm and year fixed effects. Standard errors are clustered at the firm level.

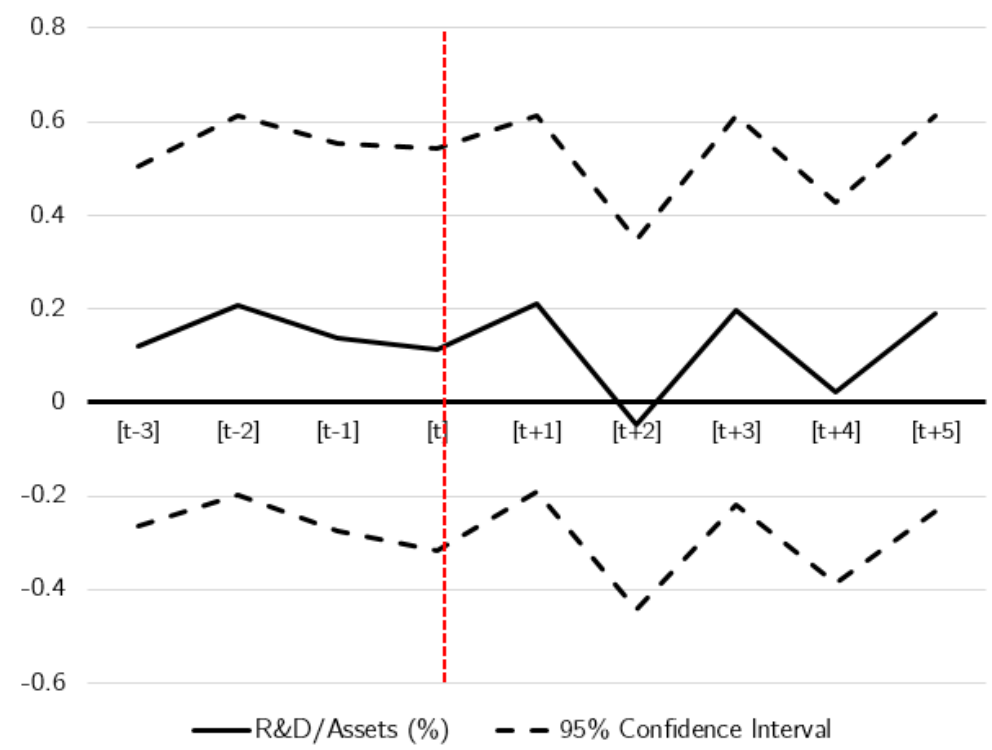

(a) R\&D/Assets 


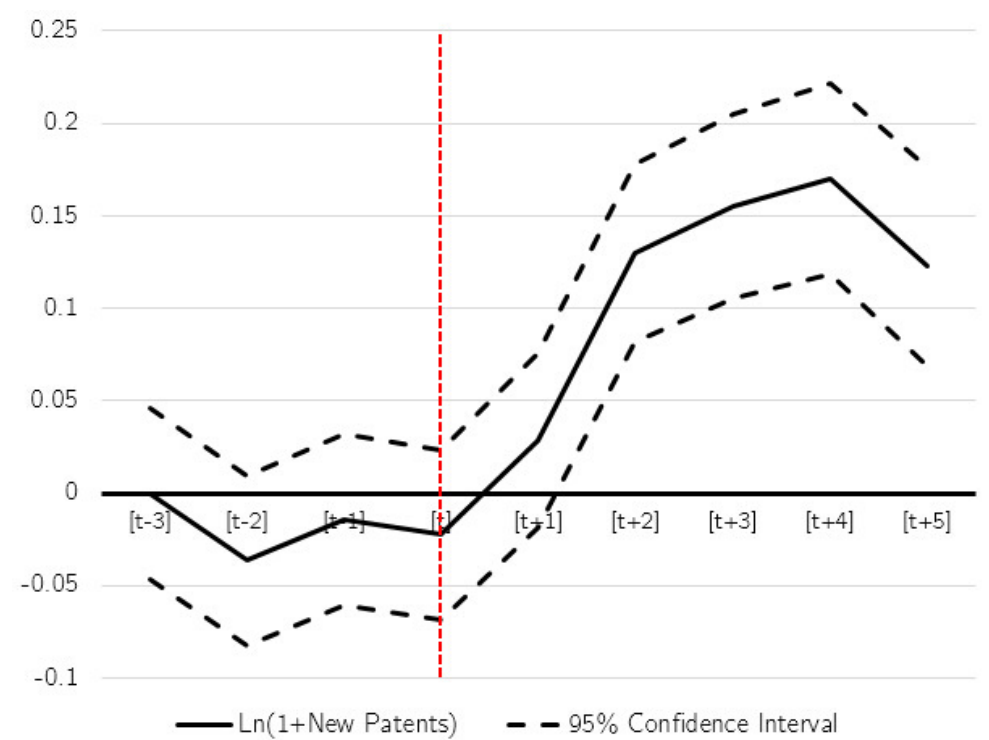

(b) New Patents

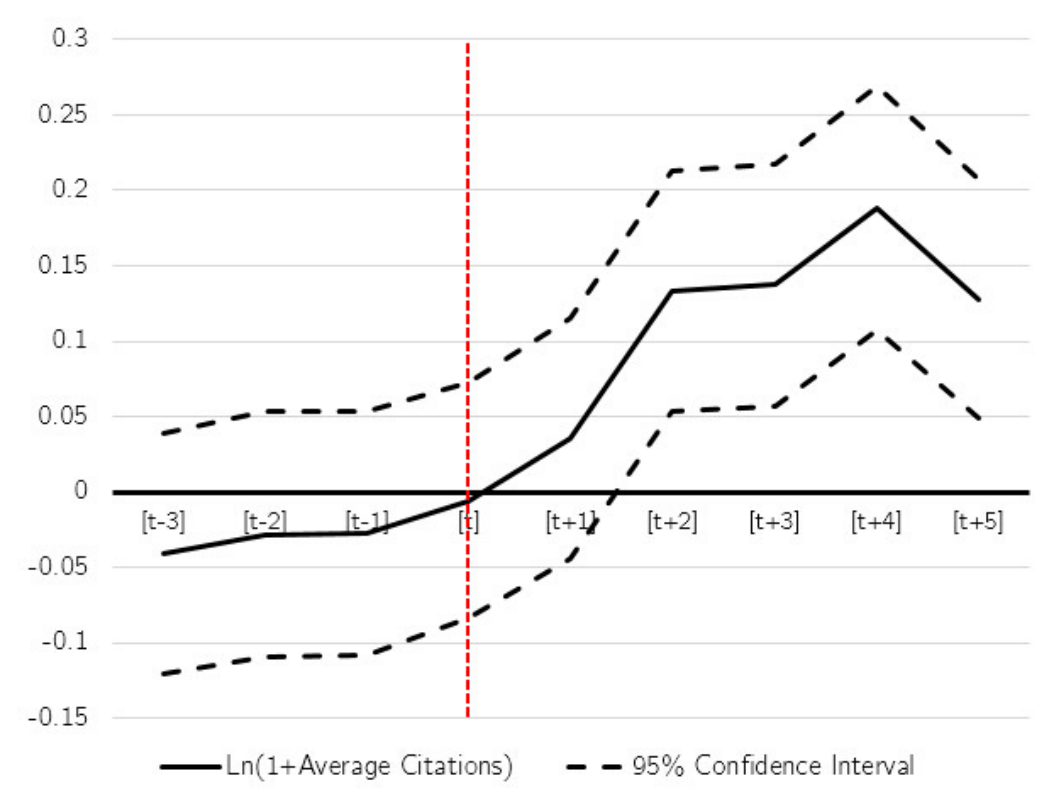

(c) Average Citations 


\section{Figure 2. Citation Dynamics Around Patent Transactions}

This figure plots the coefficients $\beta_{k}$ from the following regression at the patent $(i)$-year $(t)$ level:

$$
\text { Citation }_{i, t}=\sum_{k=-3}^{+3} \beta_{k} d[t+k]_{i, t}+\gamma \cdot \text { Patent Age } e_{i, t}+\alpha_{i}+\alpha_{t}+\varepsilon_{i, t},
$$

Citation $_{i, t}$ is the number of new citations a patent receives in a given year. The dummy variable $d[t+k]$ is equal to one if the patent observation is $k$ years from the sale of the patent, and zero otherwise. We run the regression separately for patents sold by target firms within two years following hedge fund intervention (left panel) and for patents sold by the propensity score matched non-target firms (right panel). We control for Patent Age measured as the logarithm of the patent age in year $t$. We also include year and patent fixed effects, $\alpha_{t}$ and $\alpha_{i}$. Standard errors are clustered at the firm level.

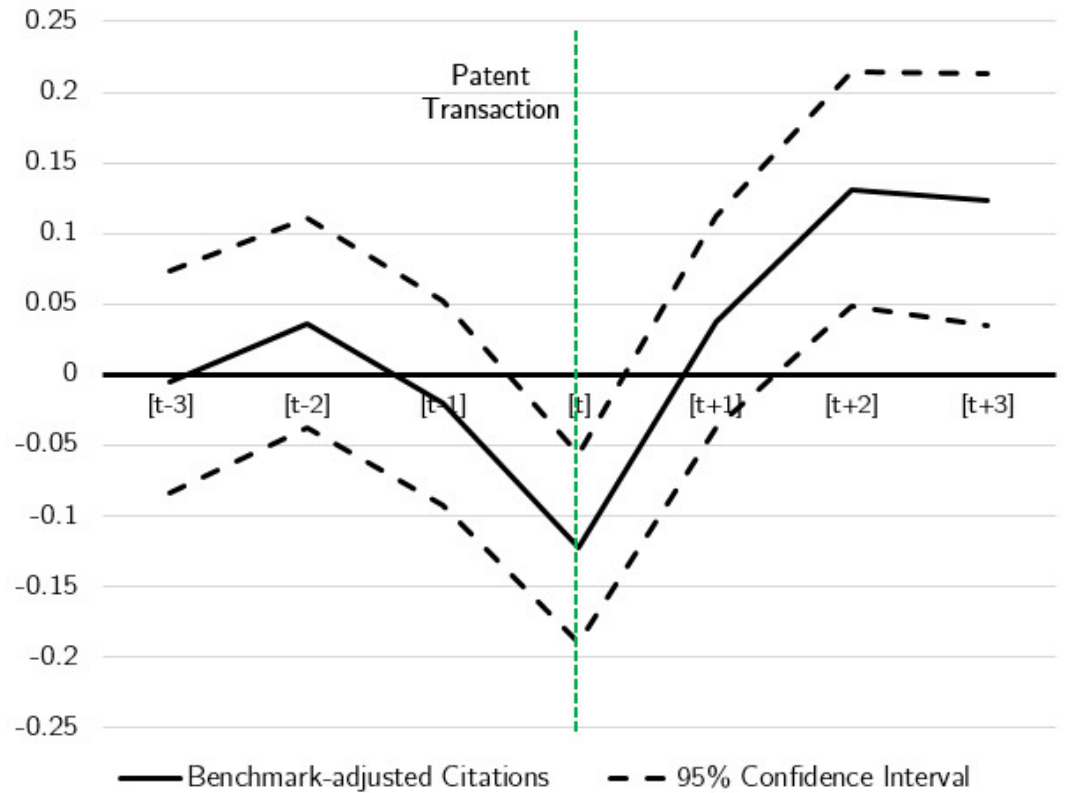

(a) Patent Sales by Targets of Hedge Fund Activists

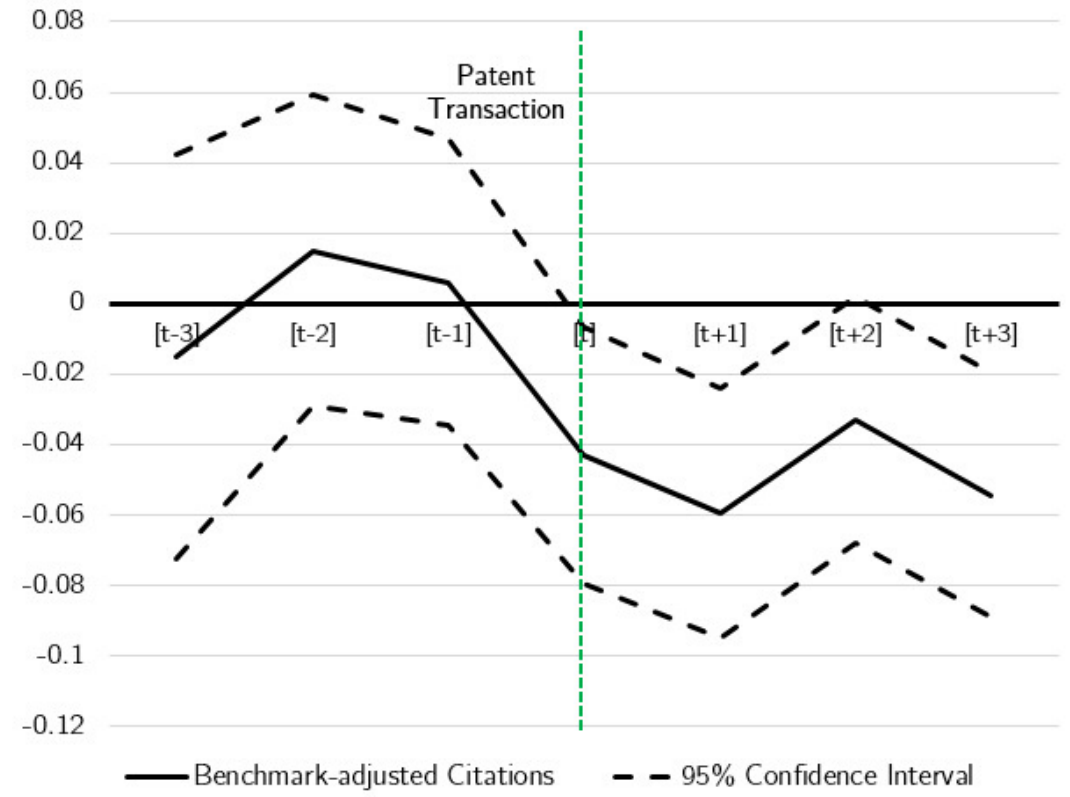

(b) Patent Sales by Matched Firms 


\section{Table 1. Hedge Fund Activism and Innovation by Year and Industry}

This table provides descriptive statistics on hedge fund activism events by year (Panel A) and by industry (Panel B). We identify hedge fund activism events through Schedule 13D filings, which are mandatory SEC disclosures of share ownership exceeding 5\% with an intention to influence corporate policy or control. We supplement these filings with news searches for events in which activists hold ownership stakes between $2 \%$ and $5 \%$ at companies with $\$ 1$ billion or more market capitalization. A target firm is broadly defined as an "innovative target" if the firm filed at least one patent in any year prior to the activism event with at least one positive R\&D expenditure within the five-year window prior to the intervention. We also report on an alternative and narrower measure for an "innovative target" requiring that the firm file at least one patent between three years and one year prior to the activism event with at least one positive R\&D expenditure within the five-year window prior to the intervention. Panel A reports the annual number of hedge fund activism events between 1994 and 2007, the proportion of innovative target firms each year, and the median number of patents owned by those target firms in the event year. Panel B reports the number of hedge fund activism events and the proportion of innovative targets across the Fama-French 12 industries.

\section{Panel A: Hedge Fund Activism by Year}

Innovative Targets: Firms that Filed a Patent in Any Year Prior to Year $t$
Innovative Targets: Firms that Filed a Patent from Year $t-3$ to Year $t-1$

\begin{tabular}{|c|c|c|c|c|c|}
\hline & (1) & (2) & (3) & (4) & (5) \\
\hline Year & \# of Events & $\%$ of Innovative Targets & $\begin{array}{c}\text { \# of Patents Owned by } \\
\text { Targets (Median) }\end{array}$ & $\%$ of Innovative Targets & $\begin{array}{c}\text { \# of Patents Owned by } \\
\text { Targets (Median) }\end{array}$ \\
\hline 1994 & 8 & $37.50 \%$ & 138 & $37.50 \%$ & 138 \\
\hline 1995 & 28 & $46.43 \%$ & 2 & $35.71 \%$ & 2 \\
\hline 1996 & 82 & $36.59 \%$ & 12 & $30.49 \%$ & 15 \\
\hline 1997 & 178 & $22.47 \%$ & 11 & $19.10 \%$ & 12.5 \\
\hline 1998 & 140 & $30.71 \%$ & 12 & $25.00 \%$ & 18 \\
\hline 1999 & 99 & $20.20 \%$ & 18 & $16.16 \%$ & 26 \\
\hline 2000 & 98 & $21.43 \%$ & 19 & $19.39 \%$ & 19 \\
\hline 2001 & 85 & $29.41 \%$ & 18 & $24.71 \%$ & 20 \\
\hline 2002 & 119 & $32.77 \%$ & 10 & $27.73 \%$ & 13.5 \\
\hline 2003 & 112 & $36.61 \%$ & 14 & $29.46 \%$ & 17 \\
\hline 2004 & 133 & $34.59 \%$ & 7 & $27.82 \%$ & 10 \\
\hline 2005 & 203 & $30.05 \%$ & 13 & $22.17 \%$ & 20 \\
\hline 2006 & 235 & $34.47 \%$ & 24 & $24.26 \%$ & 50 \\
\hline 2007 & 250 & $36.00 \%$ & 21 & $23.20 \%$ & 36 \\
\hline Full Sample & 1,770 & $31.24 \%$ & 16 & $24.07 \%$ & 24 \\
\hline
\end{tabular}


Panel B: Hedge Fund Activism by Industry

\begin{tabular}{|c|c|c|c|}
\hline & Activism Events & $\begin{array}{c}\% \text { of Innovative Targets: } \\
\text { Patent(s) Filed Anytime Prior to Year t }\end{array}$ & $\begin{array}{l}\% \text { of Innovative Targets: } \\
\text { Patent(s) Filed from Year } t-3 \text { to Year } t-1\end{array}$ \\
\hline Consumer Nondurables & 94 & $36.17 \%$ & $21.28 \%$ \\
\hline Consumer Durables & 47 & $61.70 \%$ & $59.57 \%$ \\
\hline Manufacturing & 166 & $59.04 \%$ & $46.39 \%$ \\
\hline Energy & 64 & $9.38 \%$ & $3.13 \%$ \\
\hline Chemicals and Allied Products & 33 & $60.61 \%$ & $48.48 \%$ \\
\hline High Tech & 346 & $51.45 \%$ & $41.04 \%$ \\
\hline Tele and Communications & 73 & $12.33 \%$ & $9.59 \%$ \\
\hline Utilities & 29 & $6.90 \%$ & $3.45 \%$ \\
\hline Wholesale and Retail & 225 & $9.33 \%$ & $5.78 \%$ \\
\hline Healthcare, Medical Equipment, and Drug & 192 & $53.13 \%$ & $46.35 \%$ \\
\hline Finance & 238 & $5.04 \%$ & $2.10 \%$ \\
\hline Others & 263 & $15.97 \%$ & $9.89 \%$ \\
\hline Full Sample & 1,770 & $31.24 \%$ & $24.07 \%$ \\
\hline
\end{tabular}


Table 2. Summary Statistics for the Target Firms and the Matched Control Sample

This table reports firm characteristics at the firm-year level for the subsample of innovative target firms defined as firms that filed for at least one patent that was eventually granted prior to the year of the hedge fund intervention with at least one positive R\&D expenditure within the five-year window prior to the intervention and for the control sample. The control sample is formed by matching each event firm to the non-event innovative firm from the same industry (2-digit SIC) with the closest propensity score, where the propensity score is estimated using market to book ratio both in one year and three years prior to intervention and size (logarithm of total assets). The variable values are measured as of the year prior to the hedge fund intervention. For each variable, we report the mean, standard deviation, $25^{\text {th }}, 50^{\text {th }}$ and $75^{\text {th }}$ percentiles. We also report the $t$-statistics for the differences in mean values between the target and matched firms. ***, **, and * indicate significance at the 1\%,5\%, and $10 \%$ levels, respectively. All variables are defined in Appendix A-1.

\begin{tabular}{|c|c|c|c|c|c|c|c|c|c|c|c|c|}
\hline & \multicolumn{5}{|c|}{ Targets $(\mathrm{N}=553)$} & \multicolumn{5}{|c|}{ Non-Targets $(\mathrm{N}=553)$} & \multicolumn{2}{|l|}{ Difference } \\
\hline & Mean & S.D. & $\mathrm{p} 25$ & p50 & p75 & Mean & S.D. & $\mathrm{p} 25$ & $\mathrm{p} 50$ & p75 & Target - Non-Targets & $\mathrm{t}$-Statistic \\
\hline Ln(Firm Assets) & 5.48 & 1.61 & 4.21 & 5.47 & 6.74 & 5.41 & 1.64 & 4.25 & 5.36 & 6.68 & 0.08 & $(0.76)$ \\
\hline $\operatorname{Ln}(\mathrm{MV})$ & 5.42 & 1.59 & 4.17 & 5.41 & 6.73 & 5.51 & 1.54 & 4.44 & 5.55 & 6.74 & -0.09 & $(-0.88)$ \\
\hline Firm Assets & 721.54 & 1049.17 & 67.30 & 237.49 & 849.32 & 704.06 & 1059.63 & 70.07 & 212.78 & 792.90 & 17.48 & $(0.27)$ \\
\hline MV & 631.88 & 862.10 & 63.29 & 222.16 & 814.13 & 627.49 & 848.92 & 80.15 & 234.42 & 807.43 & 4.39 & $(0.08)$ \\
\hline Firm ROA & 0.01 & 0.15 & -0.06 & 0.05 & 0.11 & 0.02 & 0.16 & -0.05 & 0.07 & 0.13 & -0.01 & $(-0.88)$ \\
\hline Firm R\&D/Assets & 0.07 & 0.08 & 0.00 & 0.03 & 0.13 & 0.07 & 0.07 & 0.00 & 0.04 & 0.11 & 0.00 & $(0.77)$ \\
\hline Leverage & 0.20 & 0.20 & 0.01 & 0.16 & 0.31 & 0.17 & 0.18 & 0.01 & 0.12 & 0.28 & $0.03 *$ & $(2.28)$ \\
\hline Firm Market-to-Book Ratio & 1.52 & 0.97 & 0.84 & 1.23 & 1.83 & 1.60 & 0.98 & 0.88 & 1.28 & 2.05 & -0.08 & $(-1.39)$ \\
\hline Ln(1+New Patents) & 0.50 & 0.72 & 0.00 & 0.00 & 1.10 & 0.53 & 0.74 & 0.00 & 0.00 & 1.10 & -0.02 & $(-0.49)$ \\
\hline Ln(1+Ave.Citation) & 0.55 & 0.98 & 0.00 & 0.00 & 0.00 & 0.55 & 0.98 & 0.00 & 0.00 & 0.53 & 0.00 & $(-0.03)$ \\
\hline Number of New Patents & 1.27 & 2.11 & 0.00 & 0.00 & 2.00 & 1.37 & 2.22 & 0.00 & 0.00 & 2.00 & -0.10 & $(-0.73)$ \\
\hline Ave. Citation of New Patents & 2.22 & 4.27 & 0.00 & 0.00 & 0.00 & 2.20 & 4.19 & 0.00 & 0.00 & 0.70 & 0.02 & $(0.09)$ \\
\hline Firm Patent Originality & 0.58 & 0.24 & 0.48 & 0.63 & 0.76 & 0.59 & 0.24 & 0.44 & 0.63 & 0.78 & -0.01 & $(-0.26)$ \\
\hline Firm Patent Generality & 0.53 & 0.27 & 0.33 & 0.57 & 0.70 & 0.54 & 0.29 & 0.35 & 0.60 & 0.73 & -0.01 & $(-0.35)$ \\
\hline Firm Patenting Explorative & 0.18 & 0.34 & 0.00 & 0.00 & 0.20 & 0.19 & 0.34 & 0.00 & 0.00 & 0.33 & -0.01 & $(-0.38)$ \\
\hline Firm Patenting Exploitative & 0.29 & 0.42 & 0.00 & 0.00 & 0.75 & 0.29 & 0.42 & 0.00 & 0.00 & 0.75 & -0.01 & $(-0.22)$ \\
\hline
\end{tabular}




\section{Table 3. Innovation Subsequent to Hedge Fund Activism}

This table documents the dynamics of inputs to and outputs from innovation around hedge fund interventions. We use the following difference-indifferences specification:

$$
y_{i, t}=\alpha_{t}+\alpha_{i}+\beta_{1} \cdot I(\text { Post }) \times I(\text { Target })+\beta_{2} \cdot I(\text { Post })+\gamma \cdot \text { Control }_{i, t}+\varepsilon_{i, t} .
$$

The sample includes hedge fund target and control firms as described in Table 2. We include observations from 5 years prior to and 5 years post intervention for both the target and matched firm. I(Target) is a dummy variable indicating whether the firm is a target of hedge fund activism, $I($ Post $)$ is a dummy variable equal to one if the target firm (matched control firm) is within $[t+1, t+5]$ years after the activism event year (the "pseudo-event" year). Panel A examines the inputs and outputs of innovation. In column (1) the dependent variable is R\&D expenditures scaled by firm assets while in column (2) the dependent variable is the raw $R \& D$ expenditures. In columns (3) and (4) the dependent variables are the natural logarithm of patent counts (plus one) and the natural logarithm of citations per patent (plus one), respectively. In columns (5) and (6) the dependent variables are the patent generality and originality scores, respectively, both described in Appendix A-1. In column (7) the dependent variable is the market value of new patents applied during the year, calculated as the market responses to the patents' approval following Kogan et al. (2015). Panel B examines specific subsamples. Column (1) constrains the sample to new patents that rank as the top 20\% most cited at the firm-year level. Columns (2) and (3) focus on the chemical, healthcare, medical equipment, and drug (CHMD) industries which tend to have long lags between R\&D and new patents. Columns (4) and (5) analyze the complement set of non-CHMD industries. Control variables include the natural logarithms of firm market capitalization and firm age. All specifications include firm and year fixed effects. The $t$-statistics based on standard errors clustered at the firm level are displayed in parentheses. $* * *, * *$, and $*$ indicate significance at the $1 \%, 5 \%$, and $10 \%$ levels, respectively. 
Panel A: Innovation inputs and outputs

\begin{tabular}{|c|c|c|c|c|c|c|c|}
\hline & $\begin{array}{c}(1) \\
\text { R\&D/Assets } \\
(\%)\end{array}$ & $\begin{array}{c}(2) \\
\text { R\&D Expenses } \\
(\$ \text { mil })\end{array}$ & $\begin{array}{c}\text { (3) } \\
\text { Log } \\
\text { (1+\# New Patents) }\end{array}$ & $\begin{array}{c}\text { (4) } \\
\text { Log } \\
\text { (1+Ave.Citations) }\end{array}$ & $\begin{array}{l}\text { (5) } \\
\text { Originality }\end{array}$ & $\begin{array}{c}\text { (6) } \\
\text { Generality }\end{array}$ & $\begin{array}{c}(7) \\
\text { Yearly Innovation } \\
\text { Value }(\$ M) \\
\end{array}$ \\
\hline $\mathrm{I}($ Target $) \times \mathrm{I}($ Post $)$ & $\begin{array}{c}-0.151 \\
(-1.323)\end{array}$ & $\begin{array}{c}-11.007 * * * \\
(-3.086)\end{array}$ & $\begin{array}{l}0.151 * * * \\
(3.711)\end{array}$ & $\begin{array}{c}0.155 * * * \\
(3.071)\end{array}$ & $\begin{array}{c}0.027 * * * \\
(2.816)\end{array}$ & $\begin{array}{c}0.009 \\
(1.109)\end{array}$ & $\begin{array}{c}12.260 * \\
(1.784)\end{array}$ \\
\hline I(Post) & $\begin{array}{c}0.061 \\
(0.430)\end{array}$ & $\begin{array}{c}4.648 \\
(1.044)\end{array}$ & $\begin{array}{l}-0.060 * \\
(-1.935)\end{array}$ & $\begin{array}{c}0.007 \\
(0.176)\end{array}$ & $\begin{array}{c}-0.049 * * * \\
(-3.973)\end{array}$ & $\begin{array}{c}-0.003 \\
(-0.279)\end{array}$ & $\begin{array}{c}-4.593 \\
(-0.584)\end{array}$ \\
\hline $\ln (\mathrm{MV})$ & $\begin{array}{c}-0.580 * * * \\
(-13.736)\end{array}$ & $\begin{array}{c}5.361 * * * \\
(4.058)\end{array}$ & $\begin{array}{c}0.047 * * * \\
(4.076)\end{array}$ & $\begin{array}{c}0.048^{* * * *} \\
(3.310)\end{array}$ & $\begin{array}{c}0.012 * * * \\
(3.476)\end{array}$ & $\begin{array}{c}0.009 * * * \\
(2.963)\end{array}$ & $\begin{array}{c}-0.435 \\
(-0.151)\end{array}$ \\
\hline $\ln ($ Age $)$ & $\begin{array}{c}0.014 \\
(0.108)\end{array}$ & $\begin{array}{c}-2.713 \\
(-0.677)\end{array}$ & $\begin{array}{c}-0.029 \\
(-0.747)\end{array}$ & $\begin{array}{c}-0.084 \\
(-1.506)\end{array}$ & $\begin{array}{l}-0.022 * \\
(-1.888)\end{array}$ & $\begin{array}{c}0.008 \\
(0.715)\end{array}$ & $\begin{array}{c}17.670 * * \\
(2.524)\end{array}$ \\
\hline Constant & $\begin{array}{c}8.872 * * * \\
(7.347)\end{array}$ & $\begin{array}{c}8.273 \\
(0.219)\end{array}$ & $\begin{array}{c}-0.009 \\
(-0.029)\end{array}$ & $\begin{array}{c}0.432 \\
(1.064)\end{array}$ & $\begin{array}{l}0.198 * \\
(1.781)\end{array}$ & $\begin{array}{c}0.021 \\
(0.274)\end{array}$ & $\begin{array}{l}-14.613 \\
(-0.129)\end{array}$ \\
\hline Observations & 9,817 & 9,817 & 9,817 & 9,817 & 3,218 & 2,763 & 3,218 \\
\hline R-squared & 0.888 & 0.909 & 0.632 & 0.555 & 0.506 & 0.460 & 0.625 \\
\hline Year FE & Yes & Yes & Yes & Yes & Yes & Yes & Yes \\
\hline Firm FE & Yes & Yes & Yes & Yes & Yes & Yes & Yes \\
\hline
\end{tabular}


Panel B. subsample evidence

\begin{tabular}{|c|c|c|c|c|c|}
\hline & \multirow{3}{*}{$\begin{array}{c}\text { (1) } \\
\begin{array}{c}\text { Quality of Top 20\% Most- } \\
\text { cited Patents }\end{array}\end{array}$} & \multicolumn{2}{|c|}{ Chemical, Healthcare, Med Equip, \& Drug (CHMD) } & \multicolumn{2}{|c|}{ Non- CHMD } \\
\hline & & (2) & (3) & (4) & $(5)$ \\
\hline & & $\log (1+\#$ New Patents $)$ & Log(1+Ave.Citations) & $\log (1+\#$ New Patents $)$ & Log(1+Ave.Citations $)$ \\
\hline \multirow[t]{2}{*}{$\mathrm{I}($ Target $) \times \mathrm{I}($ Post $)$} & $0.172 * *$ & $0.231 * * *$ & 0.143 & $0.129 * * *$ & $0.171 * * *$ \\
\hline & $(2.250)$ & $(2.919)$ & $(1.458)$ & $(2.748)$ & $(2.960)$ \\
\hline \multirow[t]{2}{*}{ I(Post) } & -0.100 & -0.077 & 0.009 & -0.053 & -0.007 \\
\hline & $(-1.462)$ & $(-1.201)$ & $(0.119)$ & $(-1.492)$ & $(-0.150)$ \\
\hline \multirow[t]{2}{*}{$\ln (\mathrm{MV})$} & $0.096 * * *$ & $0.061 * * *$ & 0.034 & $0.043 * * *$ & $0.054 * * *$ \\
\hline & $(3.683)$ & $(2.899)$ & $(1.093)$ & (3.204) & $(3.229)$ \\
\hline \multirow[t]{2}{*}{$\ln ($ Age $)$} & $-0.281 * * *$ & -0.023 & -0.059 & -0.027 & -0.076 \\
\hline & $(-3.805)$ & $(-0.323)$ & $(-0.550)$ & $(-0.587)$ & $(-1.155)$ \\
\hline \multirow[t]{2}{*}{ Constant } & 0.741 & -0.297 & 0.111 & 0.177 & 0.620 \\
\hline & $(1.433)$ & $(-0.456)$ & $(0.147)$ & $(0.796)$ & $(1.558)$ \\
\hline Observations & 9,817 & 2,138 & 2,138 & 7,679 & 7,679 \\
\hline R-squared & 0.576 & 0.660 & 0.586 & 0.626 & 0.551 \\
\hline Year FE & Yes & Yes & Yes & Yes & Yes \\
\hline Firm FE & Yes & Yes & Yes & Yes & Yes \\
\hline
\end{tabular}




\section{Table 4. Hedge Fund Activism, Innovation, and the Diversity of Innovation}

The sample consists of the hedge fund target and matched firms as described in Table 2. In Panel A we use the following specification:

$$
\begin{aligned}
y_{i, t}=\alpha_{t}+\alpha_{i} & +I(\text { HighDiv }) \cdot\left[\beta_{1} \cdot I(\text { Post }) \times I(\text { Target })+\beta_{2} \cdot I(\text { Post })\right] \\
& +I(\text { LowDiv }) \cdot\left[\beta_{3} \cdot I(\text { Post }) \times I(\text { Target })+\beta_{4} \cdot I(\text { Post })\right] \\
& +\gamma \cdot \text { Control }_{i, t}+\varepsilon_{i, t} .
\end{aligned}
$$

$I$ (Target) is a dummy variable indicating whether the firm is a target of hedge fund activism, and $I($ Post $)$ is a dummy variable equal to one if the target firm (matched control firm) is within $[\mathrm{t}+1, \mathrm{t}+5]$ years after the activism event year (the "pseudo-event" year). I(HighDiv) and I(LowDiv) are dummy variables indicating whether a firm is above or below the median in terms of its patent portfolio diversity (defined in Appendix A-1), measured at year $t-1$. In columns (1) and (2) the dependent variable is the natural logarithm of patent counts (plus one). For ease of comparison, the coefficients associated with regressors interacted with $I\left(\right.$ HighDiv), $\beta_{1}, \beta_{2}$, are reported in column (1), and those interacted with $I\left(\right.$ LowDiv), $\beta_{3}, \beta_{4}$, are reported in column (2). The $F$-test statistic (with p-value in the parentheses) for the equality of the coefficients associated with $I($ Post $) \times I($ Target) is reported in column (3). In columns (4) to (6) we perform the same analysis as in the previous three columns except that the dependent variable is replaced by the logarithm of citations per patent (plus one). The control variables include the natural logarithms of firm market capitalization and firm age. In Panel B we focus on the output from innovation at the key technology class of a firm. A technology class is defined as key (non-key) if it includes the largest (smallest) number of patents from the firm's patent stock. We use the following specification:

$$
y_{i, t}=\alpha_{t}+\alpha_{i}+\beta_{1} \cdot I(\text { Post }) \times I(\text { Target })+\beta_{2} \cdot I(\text { Post })+\gamma \cdot \text { Control }_{i, t}+\varepsilon_{i, t} .
$$

$I$ (Target) and $I$ (Post) are as defined above. The results are reported for measures calculated separately for key and non-key technology classes. In columns (1) and (2) the dependent variables are constructed by counting the number and average citations of new patents in the key technology class of a firm. In columns (3) and (4) we report on the intensity of exploration at target firms subsequent to hedge fund activism. Explorative (exploitative) measure the intensity with which a firm innovates based on knowledge that is new (old) to the firm. Appendix A-1 contains the detailed description of these variables. Columns (5) to (8) are analogous to (1) to (4) except that the measures are constructed using innovation in the non-key technology class of the firm. Control variables include the natural logarithms of firm market capitalization and firm age. All specifications include firm and year fixed effects. The $t$ statistics, based on standard errors clustered at the firm level, are displayed in parentheses. ***, **, and * indicate significance at the $1 \%, 5 \%$, and $10 \%$ levels, respectively. 
Panel A: Hedge Fund Activism, Innovation and Diversity of Innovation

\begin{tabular}{|c|c|c|c|c|c|c|}
\hline & (1) & (2) & (3) & (4) & (5) & (6) \\
\hline & \multicolumn{2}{|c|}{$\ln (1+\#$ New Patents $)$} & \multicolumn{3}{|c|}{$\ln (1+$ Ave.Cit $)$} & \multirow[b]{2}{*}{ F-Test } \\
\hline & $\begin{array}{c}\text { High } \\
\text { Diversity } \\
\end{array}$ & $\begin{array}{c}\text { Low } \\
\text { Diversity }\end{array}$ & F-Test & $\begin{array}{c}\text { High } \\
\text { Diversity }\end{array}$ & $\begin{array}{c}\text { Low } \\
\text { Diversity } \\
\end{array}$ & \\
\hline $\mathrm{I}($ Target $) \times \mathrm{I}($ Post $)$ & $\begin{array}{c}0.232 * * * \\
(4.817)\end{array}$ & $\begin{array}{c}0.062 \\
(1.201)\end{array}$ & $\begin{array}{l}5.57 * * \\
(1.90 \%)\end{array}$ & $\begin{array}{c}0.218 * * * \\
(3.559)\end{array}$ & $\begin{array}{c}0.092 \\
(1.628)\end{array}$ & $\begin{array}{c}2.01 \\
(15.78 \%)\end{array}$ \\
\hline $\mathrm{I}($ Post $)$ & $\begin{array}{l}-0.077 * * \\
(-2.152)\end{array}$ & $\begin{array}{c}-0.042 \\
(-0.828)\end{array}$ & & $\begin{array}{c}-0.008 \\
(-0.177)\end{array}$ & $\begin{array}{c}0.018 \\
(0.351)\end{array}$ & \\
\hline $\ln (\mathrm{MV})$ & \multicolumn{2}{|c|}{$\begin{array}{c}0.047 * * * \\
(4.772)\end{array}$} & \multicolumn{4}{|c|}{$\begin{array}{c}0.048 * * * \\
(3.733)\end{array}$} \\
\hline $\ln ($ Age $)$ & \multicolumn{2}{|c|}{$\begin{array}{c}-0.016 \\
(-0.464)\end{array}$} & \multicolumn{4}{|c|}{$\begin{array}{l}-0.065 \\
(-1.397)\end{array}$} \\
\hline Observations & \multicolumn{2}{|c|}{9,817} & \multicolumn{4}{|c|}{9,817} \\
\hline R-squared & \multicolumn{2}{|c|}{0.669} & \multicolumn{4}{|c|}{0.595} \\
\hline Year FE & \multicolumn{2}{|c|}{ Yes } & \multicolumn{4}{|c|}{ Yes } \\
\hline Firm FE & \multicolumn{2}{|c|}{ Yes } & \multicolumn{4}{|c|}{ Yes } \\
\hline
\end{tabular}


Panel B: Effect on Innovation Within Key and Non-Key Technology Classes

\begin{tabular}{|c|c|c|c|c|c|c|c|c|}
\hline & \multicolumn{4}{|c|}{ Key Technology Class } & \multicolumn{4}{|c|}{ Non-key Technology Class } \\
\hline & (1) & (2) & (3) & (4) & (5) & (6) & (7) & (8) \\
\hline & $\ln (1+\#$ New Patents $)$ & $\ln (1+$ Ave.Citation $)$ & Explorative & Exploitative & $\ln (1+\#$ New Patents $)$ & $\ln (1+$ Ave.Citation $)$ & Explorative & Exploitative \\
\hline \multirow[t]{2}{*}{$\mathrm{I}($ Target $) \times \mathrm{I}($ Post $)$} & $0.194 * * *$ & $0.182 * * *$ & $0.040 * * *$ & -0.045 & -0.028 & 0.027 & -0.028 & 0.016 \\
\hline & $(4.469)$ & $(3.444)$ & $(2.671)$ & $(-0.751)$ & $(-0.525)$ & $(0.503)$ & $(-0.401)$ & $(0.267)$ \\
\hline \multirow{2}{*}{ I(Post) } & -0.055 & -0.031 & -0.027 & 0.035 & -0.016 & -0.032 & -0.014 & 0.031 \\
\hline & $(-0.756)$ & $(-0.726)$ & $(-0.829)$ & $(0.603)$ & $(-0.455)$ & $(-0.747)$ & $(-0.241)$ & $(0.555)$ \\
\hline $\ln (\mathrm{MV})$ & $(6.011)$ & $(2.344)$ & $(1.943)$ & $(-0.540)$ & $(3.440)$ & $(2.379)$ & $(-0.429)$ & $(-0.321)$ \\
\hline \multirow[t]{2}{*}{$\ln ($ Age $)$} & -0.010 & $-0.114 * *$ & -0.022 & $-0.092 * *$ & $0.117 * *$ & $-0.115^{* *}$ & $-0.087 *$ & $-0.089 * *$ \\
\hline & $(-0.211)$ & $(-2.218)$ & $(-1.203)$ & $(-2.060)$ & $(2.199)$ & $(-2.215)$ & $(-1.652)$ & $(-2.022)$ \\
\hline \multirow[t]{2}{*}{ Constant } & -0.232 & 0.433 & 0.176 & $1.228 * * *$ & -0.354 & 0.429 & $1.074 * * *$ & $1.207 * * *$ \\
\hline & $(-0.897)$ & $(0.862)$ & $(1.237)$ & $(6.158)$ & $(-0.826)$ & $(0.858)$ & $(5.118)$ & $(6.982)$ \\
\hline Observations & 9,817 & 9,817 & 3,218 & 3,218 & 9,817 & 9,817 & 3,218 & 3,218 \\
\hline Firm FE & Yes & Yes & Yes & Yes & Yes & Yes & Yes & Yes \\
\hline
\end{tabular}




\section{Table 5. Patent Transactions Around Hedge Fund Activism}

This table provides evidence on patent transactions around hedge fund interventions. Patent transactions, reported in Panel A, are modeled using the following difference-in-differences specification:

$$
\begin{aligned}
y_{i, t}=\alpha_{t} & +\alpha_{S I C 3}+\beta_{1} \cdot I(\text { Target })+\beta_{2} \cdot I(\text { Post })+\beta_{3} \cdot I(\text { Post }) \times I(\text { Target }) \\
& +\gamma \cdot \text { Control }_{i, t}+\varepsilon_{i, t} .
\end{aligned}
$$

The sample consists of the hedge fund target and matched firms as described in Table 2. We include observations from 5 years prior to and 5 years post intervention for both the target and matched firm. The dependent variables are the numbers of patents bought or sold by a firm in a given year scaled by the total patents owned by the firm. Patent transactions are identified from the United States Patent and Trademark Office (USPTO) and accessed through the Google Patent database. I(Target) is a dummy variable indicating whether the firm is a target of hedge fund activism and I(Post) is a dummy variable equal to one if the target firm (matched control firm) is within $[t+1, t+5]$ years after the activism event year (the "pseudo-event" year). Control variables include the natural logarithms of firm market capitalization and firm age. All specifications also include year and industry (or firm) fixed effects. The $t$-statistics, based on standard errors clustered at the firm level, are displayed in parentheses. $* * *, * *$, and * indicate significance at the $1 \%, 5 \%$, and $10 \%$ levels, respectively.

Panel B analyzes the determinants of patent sales using a linear probability model. The key variable of interest is Distance (Patent to Firm), which measures the distance between a given patent and the firm's overall patent portfolio based on the methodology developed in Akcigit et al. (2013). The two columns vary in the value $(0.33$ and 0.66$)$ of the weighting parameter $l$ (See Appendix A-2 for a more detailed description). Before is a dummy variable equal to one for event years $t-3$ through $t$ - 1 . After is a dummy variable equal to one for event years from $t$ to $t+3$. Both Before and After are coded as zero for all observations belonging to the matched firms. All specifications include year, patent vintage, and patent technological class (or firm) fixed effects. The $t$-statistics, based on standard errors clustered at the firm level, are displayed in parentheses. $* * *, * *$, and $*$ indicate significance at the $1 \%, 5 \%$, and $10 \%$ levels, respectively.

\begin{tabular}{|c|c|c|c|c|}
\hline \multirow[b]{3}{*}{$\mathrm{I}($ Target $) \times \mathrm{I}($ Post $)$} & (1) & (2) & (3) & (4) \\
\hline & \multicolumn{2}{|c|}{$\frac{\text { Patent Sales }}{\text { Patents Owned }}($ in \%) } & \multicolumn{2}{|c|}{$\frac{\text { Patent Purchases }}{\text { Patents Owned }}$ (in \%) } \\
\hline & $\begin{array}{l}0.641 * * \\
(2.171)\end{array}$ & $\begin{array}{r}0.691 * * \\
(2.428)\end{array}$ & $\begin{array}{c}0.012 \\
(0.085)\end{array}$ & $\begin{array}{c}0.084 \\
(0.633)\end{array}$ \\
\hline I(Target) & $\begin{array}{l}-0.350 \\
(-1.257)\end{array}$ & & $\begin{array}{c}0.140 \\
(1.073)\end{array}$ & \\
\hline I(Post) & $\begin{array}{c}0.250 \\
(0.973)\end{array}$ & $\begin{array}{c}-0.212 \\
(-0.837)\end{array}$ & $\begin{array}{c}0.141 \\
(1.272)\end{array}$ & $\begin{array}{l}-0.037 \\
(-0.330)\end{array}$ \\
\hline $\ln (\mathrm{MV})$ & $\begin{array}{c}0.007 \\
(0.159)\end{array}$ & $\begin{array}{c}-0.023 \\
(-0.218)\end{array}$ & $\begin{array}{c}0.089 * * * \\
(4.285)\end{array}$ & $\begin{array}{c}0.024 \\
(0.615)\end{array}$ \\
\hline $\ln ($ Age $)$ & $\begin{array}{c}-0.276^{* * *} \\
(-2.711)\end{array}$ & $\begin{array}{c}0.420 \\
(1.424)\end{array}$ & $\begin{array}{c}-0.261^{* * * *} \\
(-3.806)\end{array}$ & $\begin{array}{l}-0.287 \\
(-1.495)\end{array}$ \\
\hline Constant & $\begin{array}{l}0.713^{*} \\
(1.911)\end{array}$ & $\begin{array}{c}-0.797 \\
(-0.743)\end{array}$ & $\begin{array}{c}4.734 \\
(1.276)\end{array}$ & $\begin{array}{c}5.041 \\
(1.360)\end{array}$ \\
\hline Observations & 9,374 & 9,374 & 9,374 & 9,374 \\
\hline R-squared & 0.028 & 0.143 & 0.029 & 0.163 \\
\hline Year FE & Yes & Yes & Yes & Yes \\
\hline Industry FE & Yes & No & Yes & No \\
\hline Firm FE & No & Yes & No & Yes \\
\hline
\end{tabular}

\section{Panel A: Patent Transaction Intensity Around Hedge Fund Activism}


Panel B: Determinants of Patent Transactions

\begin{tabular}{|c|c|c|c|c|}
\hline & (1) & (2) & (3) & (4) \\
\hline & \multicolumn{4}{|c|}{ Patent Sale $(=100 \%)$} \\
\hline & \multicolumn{2}{|c|}{ Distance Measure $(\iota=0.33)$} & \multicolumn{2}{|c|}{ Distance Measure $(\iota=0.66)$} \\
\hline Distance (Patent to Firm) & $\begin{array}{c}0.470 * * * \\
(7.990)\end{array}$ & $\begin{array}{c}0.529 * * * \\
(8.503)\end{array}$ & $\begin{array}{c}0.710 * * * \\
(10.647)\end{array}$ & $\begin{array}{c}0.701 * * * \\
(9.697)\end{array}$ \\
\hline Distance $\times$ After & $\begin{array}{c}0.132 * * \\
(2.247)\end{array}$ & $\begin{array}{c}0.283 * * * \\
(4.723)\end{array}$ & $\begin{array}{l}0.147^{*} \\
(1.712)\end{array}$ & $\begin{array}{l}0.163^{*} \\
(1.918)\end{array}$ \\
\hline Distance $\times$ Before & $\begin{array}{c}-0.090 \\
(-1.601)\end{array}$ & $\begin{array}{c}-0.260 * * * \\
(-4.444)\end{array}$ & $\begin{array}{l}-0.114^{*} \\
(-1.787)\end{array}$ & $\begin{array}{c}-0.364 * * * \\
(-5.422)\end{array}$ \\
\hline After & $\begin{array}{c}0.443 * * * \\
(10.858)\end{array}$ & $\begin{array}{c}1.082^{* * * *} \\
(9.239)\end{array}$ & $\begin{array}{c}0.423 * * * \\
(11.238)\end{array}$ & $\begin{array}{c}0.932 * * * \\
(7.115)\end{array}$ \\
\hline Before & $\begin{array}{c}-0.383 * * * \\
(-5.735)\end{array}$ & $\begin{array}{c}-0.126 * * \\
(-2.323)\end{array}$ & $\begin{array}{c}-0.523 * * * \\
(-7.208)\end{array}$ & $\begin{array}{c}-0.141 * * * \\
(-3.715)\end{array}$ \\
\hline Observations & 929,613 & 929,613 & 929,613 & 929,613 \\
\hline R-squared & 0.010 & 0.037 & 0.010 & 0.037 \\
\hline Year FE & Yes & Yes & Yes & Yes \\
\hline Patent Age FE & Yes & Yes & Yes & Yes \\
\hline Tech Class FE & Yes & Yes & Yes & Yes \\
\hline Firm FE & No & Yes & No & Yes \\
\hline
\end{tabular}




\section{Table 6. Citation Dynamics of Patents Sold Subsequent to Hedge Fund Activism}

This table analyzes the dynamics of citations around patent sales by target firms, patent sales by matched firms, and citations to patents held by firms that purchased patents from target firms. Patent sales under consideration must take place within the first two years of the activist intervention (or the pseudo-event year). The regression specification, at the patent $(j)$-year $(t)$ level, is as follows:

$$
\text { Citation }_{j, t}=\sum_{k=-3}^{+3} \beta_{k} d[t+k]_{j, t}+\gamma \cdot \text { Control }_{j, t}+\alpha_{j}+\alpha_{t}+\varepsilon_{i, t}
$$

Column (1) provides the regression results for patents sold by target firms. Column (2) provides similar evidence but for patents sold by matched firms. In column (3) we report the citation dynamics of the top patents held by matched firms, defined as patents whose citation increase over the ensuing three years ranks in the top quintile among all patents held by the matched firm. Column (4) presents evidence based on top patents held by patent buyers. Patent buyers are those firms that purchased patents from the hedge fund targets, and we define their top patents analogously. The dependent variable is the number of new citations a patent receives in a given year. The dummy variable $d[t+k]$ is equal to one if the observation is $k$ years from the sale of a patent, and zero otherwise. At the bottom of each panel we report estimates for the change in citations in the periods before and after the event year, $[t]-[t-3]$ and $[t+3]-[t]$ and the associated p-values. In columns (2) to (4) we test for differences in the trends in the period after the sale, measured relative to the trend in citations by patents sold by target firms reported in column (1), ([t+3]-[t]) $\mathrm{x}$ (Targets - Counterfactual). We control for the natural logarithm of patent age. All specifications include year, patent, or technology-class fixed effects. In all panels, $t$-statistics based on standard errors clustered at the firm level are displayed in parentheses. $* * *, * *$, and * indicate significance at the $1 \%, 5 \%$, and $10 \%$ levels, respectively. 


\begin{tabular}{|c|c|c|c|c|}
\hline & $\begin{array}{c}(1) \\
\text { Patents Sold } \\
\text { by Target } \\
\text { Firms }\end{array}$ & $\begin{array}{c}\text { (2) } \\
\text { Patents Sold } \\
\text { by Non- } \\
\text { target firms }\end{array}$ & $\begin{array}{c}(3) \\
\text { Best Patents } \\
\text { Kept by } \\
\text { Control } \\
\text { Firms } \\
\end{array}$ & $\begin{array}{c}(4) \\
\text { Best Patents } \\
\text { Kept by } \\
\text { Patent } \\
\text { Buyers } \\
\end{array}$ \\
\hline$d[t-3]$ & $\begin{array}{c}-0.005 \\
(-0.124)\end{array}$ & $\begin{array}{c}-0.015 \\
(-0.513)\end{array}$ & $\begin{array}{c}-0.036 \\
(-1.334)\end{array}$ & $\begin{array}{c}-0.023 \\
(-1.138)\end{array}$ \\
\hline $\mathrm{d}[\mathrm{t}-2]$ & $\begin{array}{c}0.036 \\
(0.956)\end{array}$ & $\begin{array}{c}0.015 \\
(0.666)\end{array}$ & $\begin{array}{c}-0.014 \\
(-0.441)\end{array}$ & $\begin{array}{c}-0.029 \\
(-1.235)\end{array}$ \\
\hline $\mathrm{d}[\mathrm{t}-1]$ & $\begin{array}{c}-0.020 \\
(-0.546)\end{array}$ & $\begin{array}{c}0.006 \\
(0.293)\end{array}$ & $\begin{array}{l}-0.057 * \\
(-1.770)\end{array}$ & $\begin{array}{c}-0.030 \\
(-1.254)\end{array}$ \\
\hline $\mathrm{d}[\mathrm{t}]$ & $\begin{array}{c}-0.123 * * * \\
(-3.630)\end{array}$ & $\begin{array}{l}-0.043 * * \\
(-2.324)\end{array}$ & $\begin{array}{c}-0.033 \\
(-1.453)\end{array}$ & $\begin{array}{l}-0.042 * \\
(-1.781)\end{array}$ \\
\hline $\mathrm{d}[\mathrm{t}+1]$ & $\begin{array}{c}0.037 \\
(0.966)\end{array}$ & $\begin{array}{c}-0.060 * * * \\
(-3.299)\end{array}$ & $\begin{array}{c}0.009 \\
(0.304)\end{array}$ & $\begin{array}{l}0.049 * \\
(1.728)\end{array}$ \\
\hline $\mathrm{d}[\mathrm{t}+2]$ & $\begin{array}{c}0.131 * * * \\
(3.095)\end{array}$ & $\begin{array}{l}-0.033^{*} \\
(-1.847)\end{array}$ & $\begin{array}{l}0.056^{*} \\
(1.718)\end{array}$ & $\begin{array}{c}0.082 * * \\
(2.331)\end{array}$ \\
\hline $\mathrm{d}[\mathrm{t}+3]$ & $\begin{array}{c}0.124 * * * \\
(2.711)\end{array}$ & $\begin{array}{c}-0.054 * * * \\
(-3.074)\end{array}$ & $\begin{array}{c}0.065^{* *} \\
(2.413)\end{array}$ & $\begin{array}{c}0.084 * * \\
(2.401)\end{array}$ \\
\hline Observations & $1,291,915$ & $1,291,915$ & $1,291,915$ & $1,291,915$ \\
\hline R-squared & 0.447 & 0.449 & 0.451 & 0.442 \\
\hline $\begin{array}{l}\text { Year FE } \\
\text { Patent FE }\end{array}$ & $\begin{array}{l}\text { Yes } \\
\text { Yes }\end{array}$ & $\begin{array}{l}\text { Yes } \\
\text { Yes }\end{array}$ & $\begin{array}{l}\text { Yes } \\
\text { Yes }\end{array}$ & $\begin{array}{l}\text { Yes } \\
\text { Yes }\end{array}$ \\
\hline F-Test & & & & \\
\hline$[\mathrm{t}]-[\mathrm{t}-3]$ & 6.67 & 0.72 & 0.04 & 1.31 \\
\hline p-val & $0.01 \%$ & $39.50 \%$ & $83.84 \%$ & $25.22 \%$ \\
\hline$[t+3]-[t]$ & 23.31 & 0.24 & 5.02 & 11.50 \\
\hline p-val & $0.00 \%$ & $62.47 \%$ & $2.72 \%$ & $0.00 \%$ \\
\hline$([\mathrm{t}]-[\mathrm{t}-3]) \times($ Targets - Counterfactual) & -- & 0.00 & 2.53 & 1.52 \\
\hline p-val & -- & $96.92 \%$ & $11.23 \%$ & $21.80 \%$ \\
\hline$([\mathrm{t}+3]-[\mathrm{t}]) \times$ (Targets - Counterfactual) & -- & 6.12 & 4.74 & 3.77 \\
\hline p-val & -- & $1.34 \%$ & $2.91 \%$ & $5.23 \%$ \\
\hline
\end{tabular}




\section{Table 7. Inventor Mobility Around Hedge Fund Activism}

This table analyzes inventor mobility around hedge fund interventions (Panel A) and associated changes in inventor productivity subsequent to inventor turnover (Panel B). The sample consists of hedge fund targets and matched firms as described in Table 2. A "leaver" is an inventor who leaves her firm during a given year, who generated at least one patent in the firm before the year of leaving, and who generates at least one patent in a different firm afterwards. A "new hire" is an inventor who has been newly hired by a given firm in a given year, who generated at least one patent in a different firm before the year of hiring, and who generates at least one patent in the current firm afterwards. A "stayer" is an inventor who stays with her firm during a given year and who generated at least one patent both before and after the year of intervention (or the pseudo-event year). An inventor is considered as generating a patent if she files for a patent during the relevant time period and that request is ultimately granted. Panel A adopts the following difference-in-differences specification at the firm $(i)$-year $(t)$ level:

$$
\begin{aligned}
y_{i, t}=\alpha_{t} & +\alpha_{\text {SIC } 3 / i}+\beta_{1} \cdot I(\text { Target })+\beta_{2} \cdot I(\text { Post })+\beta_{3} \cdot I(\text { Post }) \times I(\text { Target }) \\
& +\gamma \cdot \text { Control }_{i, t}+\varepsilon_{i, t} .
\end{aligned}
$$

$I$ (Target) is a dummy variable indicating whether the firm is a target of hedge fund activism and $I($ Post) is a dummy variable equal to one if the target firm (matched control firm) is within $[t+1, t+5]$ years after the activism event year (the pseudo-event year). Control variables include the natural logarithms of firm market capitalization and firm age. The dependent variables in columns (1) and (2) are the natural logarithm of the number of leaving inventors (plus one) and the number of newly hired inventors (plus one), respectively. All the specifications include year and industry (or firm) fixed effects. Panel B adopts a similar specification as in Panel A but at the inventor-year level on two cross sections. The dependent variable is the change in an inventor's productivity between two three-year periods. In the first, the difference is taken between [t-3, t-1] and [t-6, t-4], where $t$ is the event (or pseudo-event) year. In the second cross section (defined as post-event, or $I($ Post $)=1$ ), the difference is taken between $[\mathrm{t}, \mathrm{t}+2]$ and $[\mathrm{t}-$ $3, \mathrm{t}-1]$. The $t$-statistics based on standard errors clustered at the firm level are displayed in parentheses. $* * *, * *$, and $*$ indicate significance at the $1 \%, 5 \%$, and $10 \%$ levels, respectively.

\section{Panel A: Inventor Mobility Subsequent to Hedge Fund Activism}

\begin{tabular}{lcccc}
\hline & $(1)$ & $(2)$ & $(3)$ & $(4)$ \\
& $\ln (1+$ leavers $)$ & $\ln (1+$ leavers $)$ & $\ln (1+$ new hires $)$ & $\ln (1+$ new hires $)$ \\
\cline { 2 - 4 } I(Target) $\times$ I(Post) & & & & \\
& $0.067^{*}$ & $0.062^{*}$ & $0.081^{* * *}$ & $0.086^{* * *}$ \\
I(Target) & $(1.831)$ & $(1.664)$ & $(2.925)$ & $(3.184)$ \\
& 0.034 & & 0.008 & \\
I(Post) & $(0.889)$ & & $(0.266)$ & $-0.047^{* *}$ \\
& -0.044 & -0.019 & $-0.071^{* * *}$ & $(-2.399)$ \\
$\ln ($ MV) & $(-1.365)$ & $(-0.812)$ & $(-2.791)$ & $0.017^{* * *}$ \\
& $0.094^{* * *}$ & $0.025^{* * *}$ & $0.080^{* * *}$ & $(2.674)$ \\
$\ln ($ Age $)$ & $(9.939)$ & $(2.613)$ & $(10.090)$ & 0.004 \\
& 0.019 & 0.053 & 0.003 & $(0.144)$ \\
Constant & $(0.943)$ & $(1.275)$ & $(0.200)$ & 0.134 \\
& $-0.507^{* * *}$ & -0.146 & -0.245 & $(0.695)$ \\
Observations & $(-2.914)$ & $(-0.743)$ & $(-1.327)$ & 9,817 \\
R-squared & & & 0.545 \\
Year FE & 9,817 & 9,817 & 9,817 & Yes \\
Industry FE & 0.298 & 0.618 & 0.267 & No \\
Firm FE & Yes & Yes & Yes & Yes \\
\hline
\end{tabular}


Panel B: Inventor Change in Productivity Subsequent to Hedge Fund Activism

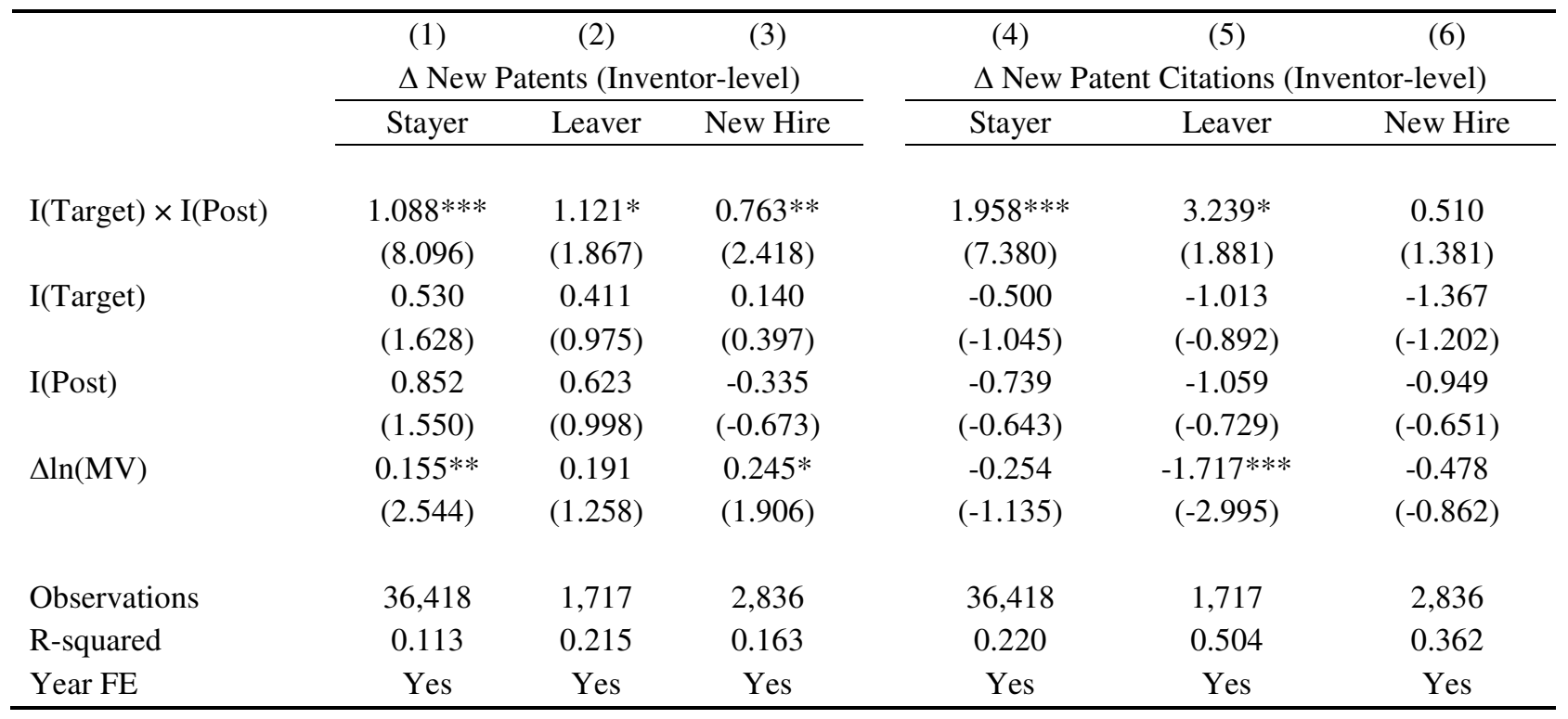




\section{Table 8. Innovation Subsequent to Hostile Hedge Fund Activism}

This table reproduces the analysis in Table 3 but with the subset of innovative targets of hostile engagements and their propensity-score-matched control firms. We report the dynamics of inputs to and outputs from innovation around these hostile interventions. We use the following difference-in-differences specification:

$$
y_{i, t}=\alpha_{t}+\alpha_{i}+\beta_{1} \cdot I(\text { Post }) \times I(\text { Target })+\beta_{2} \cdot I(\text { Post })+\gamma \cdot \text { Control }_{i, t}+\varepsilon_{i, t} .
$$

We include observations from 5 years prior to and 5 years post intervention for both target and matched firms. $I($ Target $)$ is a dummy variable indicating whether the firm is a target of hedge fund activism, and I(Post) is a dummy variable equal to one if either the target firm or its matched control firm is within $[t+1, t+5]$ years after the activism event year (or the pseudo-event year). In column (1) the dependent variable is R\&D expenditures scaled by firm assets while in column (2) the dependent variable is the raw R\&D expenditures. In columns (3) and (4) the dependent variables are the natural logarithm of patent counts (plus one) and the natural logarithm of citations per patent (plus one), respectively. In Column (5) we examine the right-tail of the distribution of subsequent citations by performing the analysis on the average citations of the top 20\% of most cited patents produced by firm $i$ in year $t$. In columns (6) and (7) the dependent variables are the patent generality and originality scores, respectively, both described in Appendix A-1. Control variables include the natural logarithms of firm market capitalization and firm age. All specifications include firm and year fixed effects. The $t$-statistics based on standard errors clustered at the firm level are displayed in parentheses. $* * *, * *$, and * indicate significance at the $1 \%, 5 \%$, and $10 \%$ levels, respectively.

\begin{tabular}{|c|c|c|c|c|c|c|c|}
\hline & $\begin{array}{c}(1) \\
\text { R\&D/Assets } \\
(\%)\end{array}$ & $\begin{array}{c}(2) \\
\text { R\&D Expenses } \\
(\$ \text { mil })\end{array}$ & $\begin{array}{c}(3) \\
\ln (1+\# \text { New Patents })\end{array}$ & $\begin{array}{c}(4) \\
\ln (1+\text { Ave.Citations })\end{array}$ & $\begin{array}{c}(5) \\
\text { Quality of Top } \\
20 \% \text { Patents } \\
\end{array}$ & $\begin{array}{c}(6) \\
\text { Originality }\end{array}$ & $\begin{array}{c}(7) \\
\text { Generality }\end{array}$ \\
\hline $\mathrm{I}($ Target $) \times \mathrm{I}($ Post $)$ & $\begin{array}{c}-0.135 \\
(-1.072)\end{array}$ & $\begin{array}{c}-14.014 * \\
(-1.930)\end{array}$ & $\begin{array}{l}0.148 * \\
(1.686)\end{array}$ & $\begin{array}{l}0.135^{*} \\
(1.718)\end{array}$ & $\begin{array}{c}0.154 \\
(1.030)\end{array}$ & $\begin{array}{c}0.018 \\
(1.015)\end{array}$ & $\begin{array}{c}0.009 \\
(0.579)\end{array}$ \\
\hline I(Post) & $\begin{array}{c}0.318 \\
(1.345)\end{array}$ & $\begin{array}{c}1.005 \\
(0.117)\end{array}$ & $\begin{array}{c}-0.047 \\
(-0.692)\end{array}$ & $\begin{array}{c}0.031 \\
(0.412)\end{array}$ & $\begin{array}{c}-0.084 \\
(-0.557)\end{array}$ & $\begin{array}{c}-0.028 \\
(-1.305)\end{array}$ & $\begin{array}{c}-0.006 \\
(-0.344)\end{array}$ \\
\hline $\ln (\mathrm{MV})$ & $\begin{array}{c}-0.409 * * * \\
(-5.598)\end{array}$ & $\begin{array}{l}6.680 * * \\
(2.523)\end{array}$ & $\begin{array}{c}0.077 * * * \\
(3.080)\end{array}$ & $\begin{array}{c}0.086 * * * \\
(3.201)\end{array}$ & $\begin{array}{c}0.157 * * * \\
(2.807)\end{array}$ & $\begin{array}{c}0.024 * * * \\
(3.748)\end{array}$ & $\begin{array}{l}0.016 * * \\
(2.575)\end{array}$ \\
\hline $\ln ($ Age $)$ & $\begin{array}{c}-0.085 \\
(-0.357)\end{array}$ & $\begin{array}{c}-25.890 * * * \\
(-2.994)\end{array}$ & $\begin{array}{c}0.057 \\
(0.593)\end{array}$ & $\begin{array}{c}0.050 \\
(0.447)\end{array}$ & $\begin{array}{c}-0.015 \\
(-0.091)\end{array}$ & $\begin{array}{c}0.032 \\
(1.384)\end{array}$ & $\begin{array}{c}0.027 \\
(1.165)\end{array}$ \\
\hline Constant & $\begin{array}{c}7.554 * * * \\
(7.668)\end{array}$ & $\begin{array}{c}117.408 * * * \\
(3.286)\end{array}$ & $\begin{array}{l}-0.645^{*} \\
(-1.779)\end{array}$ & $\begin{array}{l}-0.709 * \\
(-1.675)\end{array}$ & $\begin{array}{c}-0.806 \\
(-1.209)\end{array}$ & $\begin{array}{c}-0.235^{* * *} \\
(-2.603)\end{array}$ & $\begin{array}{l}-0.177 * * \\
(-2.070)\end{array}$ \\
\hline Observations & 2,143 & 2,143 & 2,143 & 2,143 & 2,143 & 649 & 537 \\
\hline R-squared & 0.873 & 0.894 & 0.661 & 0.545 & 0.612 & 0.520 & 0.442 \\
\hline Year FE & Yes & Yes & Yes & Yes & Yes & Yes & Yes \\
\hline Firm FE & Yes & Yes & Yes & Yes & Yes & Yes & Yes \\
\hline
\end{tabular}




\section{Table 9. Innovation Subsequent to Hedge Fund Activism - Activists' Switch in Filing Status from Schedule 13G to Schedule 13D}

This table documents the dynamics of inputs to and outputs from innovation around changes in the hedge fund filing status from a schedule 13G (passive block holding) to a schedule 13D (activist block holding). We use the following difference-in-differences specification:

$$
y_{i, t}=\alpha_{t}+\alpha_{i}+\beta_{1} \cdot I(\text { Post }) \times I(13 G \text { to } 13 D)+\beta_{2} \cdot I(\text { Post })+\gamma \cdot \text { Control }_{i, t}+\varepsilon_{i, t} .
$$

The full sample includes all firms in which we observe the filing of a Schedule $13 \mathrm{G}$, and the subsample of switches includes those for which we observe a subsequent switch to a filing of a Schedule 13D. The sample is restricted to Schedule $13 \mathrm{G}$ filings made by activist hedge funds, defined as hedge funds that had filed at least one Schedule 13D at an innovative target firm in our sample, and further restricted to those firms that had filed at least one patent prior to the Schedule $13 \mathrm{G}$ filing. Finally, the sample includes observations from 5 years prior to and 5 years post filing. $I(13 G$ to $13 D)$ is a dummy variable equal to one if there is a 13-G to-13D switch for a firm during the year (as opposed to remaining with the Schedule $13 \mathrm{G}$ status). I(Post) is a dummy variable equal to one if the firm-year observation is within $[\mathrm{t}+1, \mathrm{t}+5]$ years after the event year, where the event year is the year of the schedule $13 \mathrm{G}$ filing for the nonswitchers or the year of the switch for the switch subsample. In column (1) the dependent variable is R\&D expenditures scaled by firm assets. In columns (2) and (3) the dependent variables are the natural logarithm of patent counts (plus one) and the natural logarithm of citations per patent (plus one), respectively. Control ${ }_{i, t}$ is a vector of control variables, including the natural logarithms of market capitalization and firm age. All specifications include firm, hedge fund, and year fixed effects. The $t$ statistics based on standard errors clustered at the firm level are displayed in parentheses. ***, **, and * indicate significance at the $1 \%, 5 \%$, and $10 \%$ levels, respectively.

\begin{tabular}{lccc}
\hline & $(1)$ & $(2)$ & $(3)$ \\
& R\&D/Assets $(\%)$ & $\ln (1+\#$ New Patents $)$ & $\ln (1+$ Ave.Citation $)$ \\
\hline I(13G to 13D) & -0.101 & $0.116^{*}$ & $0.174^{* *}$ \\
& $(-0.215)$ & $(1.946)$ & $(1.968)$ \\
I(Post) & 0.008 & -0.014 & -0.009 \\
& $(0.064)$ & $(-0.713)$ & $(-0.304)$ \\
Controls & & & \\
Observations & Yes & Yes & Yes \\
R-squared & 6,756 & 6,756 & 6,756 \\
Year FE & 0.899 & 0.631 & 0.573 \\
Hedge Fund FE & Yes & Yes & Yes \\
Firm FE & Yes & Yes & Yes \\
\hline
\end{tabular}




\section{Table 10. Market Reactions to Patent Grant Announcements}

This table analyzes market reactions to the announcement of patent grants in the period before and after the arrival of hedge fund activists. Panel A provides summary statistics on the number and frequency of patent grants whose application dates by target firms (propensity-score-matched firms) all took place prior to the filing of a Schedule 13D (pseudo-event day for the controls). The time window [t-6,t-1] is defined as the six-month interval prior to the filing of Schedule 13D (pseudo-event day for the controls). The time window $[t, t+6]$ is defined as the six-month time interval after the filing of Schedule 13D (pseudo-event day for the controls). Total Patent Applications [t-48,t-1] is the sample of patent applications, which were eventually granted, that target (control) firms applied for within the 48-month period prior to the event (pseudo-event). Lag between application and grant gives the median and standard deviation of the number of months between application and grant days. Panel B provides regression results for the change-in-price reaction to patent grant news from grant years $[t-N, t-1]$ to $[t, t+N]$ ( $N=3,6$ months). Abnormal returns to patent grant news are measured by the 5-day cumulative abnormal return centered on patent grant dates in basis points, benchmarked against the CRSP value-weight market return. In column (1) and (2) the sample consists of all the patents applied by the target and control firms within 48-months prior to the event and subsequently granted within the 12-month (6-month) window around the Schedule 13D filing (pseudo-event date). I(Target) is a dummy variable indicating whether the patent belongs to a target of a hedge fund activist and zero if the patent belongs to the matched firm. The target firms' event date is assigned to their corresponding control firms as a pseudo-event date. I(Post) is a dummy variable equal to one if the patent is granted after the filing (or the pseudo-event date). Columns (3) and (4) report a similar analysis on a different sample of pooled event and control firms. The event sample is the subset of target firms for which activists switched their filings from a Schedule 13G to a Schedule 13D. The control sample consists of those innovative firms in which the same activists filed a Schedule 13G filing without a subsequent switch to a Schedule 13D filings (see Table 9). I(13G to 13D) is a dummy variable equal to one if there is a $13 \mathrm{G}$-to-13D switch. I(Post) is a dummy variable equal to one if the patent is granted after the event, where the event is the day of the switch for the event firms and is the day of the schedule $13 \mathrm{G}$ filing for the control firms. All specifications control firm fixed effects and the monthly fixed effects of the patent application-grant lag. The $t$-statistics based on standard errors clustered at the firm level are displayed in parentheses. $* * *, * *$, and * indicate significance at the $1 \%, 5 \%$, and $10 \%$ levels, respectively.

\section{Panel A: Patent Grant Dates Centered Around Hedge Fund Interventions}

\begin{tabular}{|c|c|c|}
\hline & Targets & Non-Targets \\
\hline \multicolumn{3}{|l|}{ Total Patent Applications [t-48,t-1] } \\
\hline$\%$ of Patent Grants [t-6,t-1] & $9.22 \%$ & $9.83 \%$ \\
\hline$\%$ of Patent Grants $[t, t+6]$ & $9.58 \%$ & $9.77 \%$ \\
\hline$\%$ of Patent Grants $[\mathrm{t}-3, \mathrm{t}-1]$ & $4.63 \%$ & $4.99 \%$ \\
\hline$\%$ of Patent Grants $[\mathrm{t}, \mathrm{t}+3]$ & $5.07 \%$ & $4.85 \%$ \\
\hline \multicolumn{3}{|l|}{ Lag between application and grant dates (months) } \\
\hline Median & 30 & 31 \\
\hline Standard deviation & 17.83 & 18.40 \\
\hline Average lifetime citations & 5.662 & 6.091 \\
\hline Number of firms & 373 & 389 \\
\hline
\end{tabular}




\section{Panel B: Price Reactions to Patent Grants}

\begin{tabular}{|c|c|c|c|c|}
\hline & \multicolumn{4}{|c|}{ Abnormal Return (in bps) } \\
\hline & (1) & (2) & (3) & (4) \\
\hline $\begin{array}{l}\text { Granting window } \\
\text { (months relative to intervention) }\end{array}$ & {$[t-6, t+6]$} & {$[\mathrm{t}-3, \mathrm{t}+3]$} & {$[t-6, t+6]$} & {$[\mathrm{t}-3, \mathrm{t}+3]$} \\
\hline I(Target) x I(Post) & $\begin{array}{c}32.928 * * \\
(2.489)\end{array}$ & $\begin{array}{c}30.972 * \\
(1.712)\end{array}$ & & \\
\hline $\mathrm{I}(13 \mathrm{G}$ to $13 \mathrm{D})$ & & & $\begin{array}{c}45.444 * * \\
(2.353)\end{array}$ & $\begin{array}{l}36.473 \\
(1.253)\end{array}$ \\
\hline $\mathrm{I}($ Post $)$ & $\begin{array}{c}-3.335 \\
(-0.222)\end{array}$ & $\begin{array}{c}4.782 \\
(0.876)\end{array}$ & $\begin{array}{l}-3.793 \\
(-0.331)\end{array}$ & $\begin{array}{c}-8.332 \\
(-0.571)\end{array}$ \\
\hline Observations & 4,885 & 2,527 & 3,338 & 2,384 \\
\hline R-squared & 0.168 & 0.274 & 0.157 & 0.172 \\
\hline Monthly fixed effects of application-approval lag & Yes & Yes & Yes & Yes \\
\hline Firm FE & Yes & Yes & Yes & Yes \\
\hline
\end{tabular}

